Journal of Engineering Sciences, Assiut University, Vol. 37, No. 3, pp. 743-778, May 2009.

\title{
ENVIRONMENTAL STUDY FOR DEVELOPER HISTORICAL ZONES IN TOWNS OF HADHRAMOUT VALLEY
}

\section{Bazara T.G, AL-Sagaf M.A and AL-Sagaf O.A}

Department of Architecture Environmental Planning, Faculty of

Engineering \& Petroleum Hadramout University of science \& Technology

(Received August 27, 2008 Accepted May 13, 2009)

Heritage and historical zones is considered very important for its palaces, administrative buildings, historical and old zones in these cities.

In the last two decades these cities had a problem of developing by new architecture by using skeleton of concrete and modern materials. All these give a minus effect upon the style of the there zones.

This research aimed to resolve the environmental effects to develop these zones in the field of streets, transportations and pedestrian, green areas, in and around these historical buildings in these old areas.

Thus that research takes care with these cities in Hadhramout valley and the heritage civilization of it, studding the case of climate and how to protect from it.

Then the research give an idea about cases of treatment for urban and environment in these zones. That gives us the important of urban planning and environmental studies to serve the economical, social and touristic regards in these cities.

Final the research gives us the important results and the recommendations which we could recognize our aims for having heritage and environmental urban and suitable zones in our cities in Hadhramout valley.
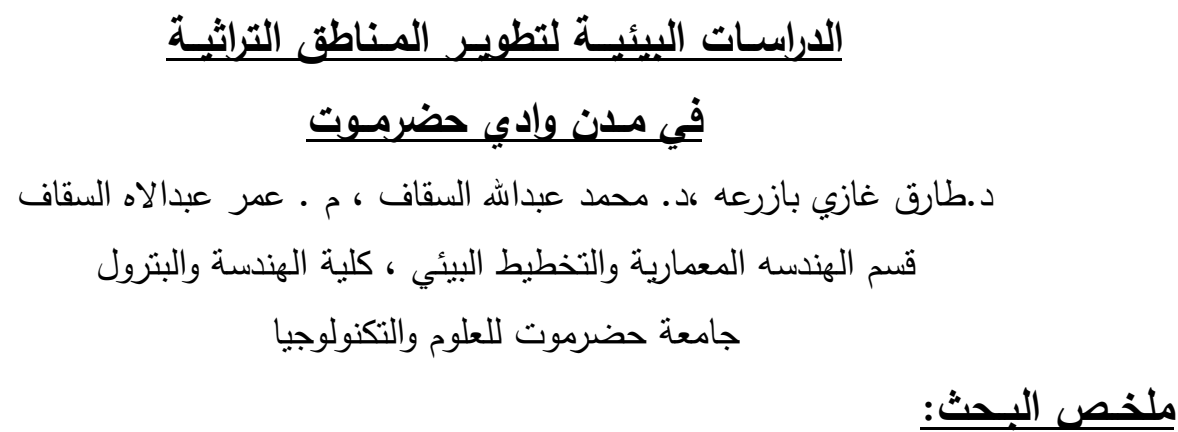

تعتبر المناطق التاريخية والتراثية بمدن وادي حضرموت ذات أهمية بالغة لما تحتويه من تراث ممثلاً في القصـور والمبـاني الإداريـة الهامـة والمنـاطق القديمـة والتاريخيـة بهـا ــ وقد تعرضــت المـدن في وادي حضرموت في العقدين الأخيرين لنوع من التنميـة الحضرية وإنشـاء المباني بـالمواد الحديثة والخرسـانية والتي أثرت بالسلب على طابع هذه المناطق • 
ويهدف البحث إلى الإهتمام بمعالجة الجوانب البيئية لنطوير هذه المناطق من حيث الإهتمام بالطرق والمرور الآلي وحركة مرور المشاة وتهيئة بعض المساحات الخضراء كحدائق ومتنفس للسكان وتهيئة

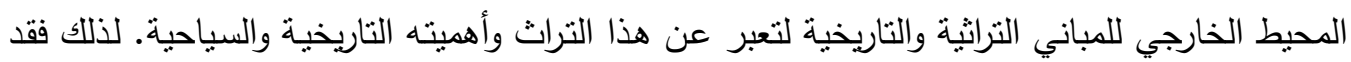
إهتم البحث بإستعراض أهمية مدن وادي حضرموت والتراث الحضاري بها. واستعرض حالة المنات الهناخ وأثثره وكيفية الحماية منه. . ثم إستعرض التراث الحضاري بمدن وادي حضرموت والمناطق القديمة والتاريخية

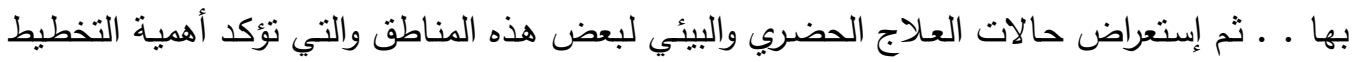

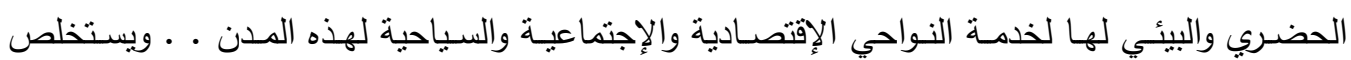

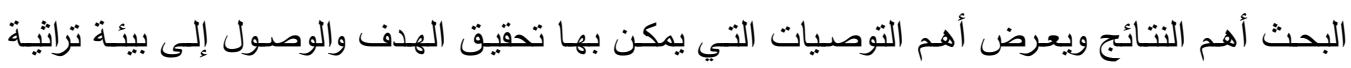
وحضرية مناسبة بمدن وادي حضرموت .

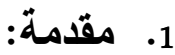

كان وادي حضرموت من أنسب المناطق استنطاناً في الجزيرة العربيـة في العصر البرونزي. بسبب

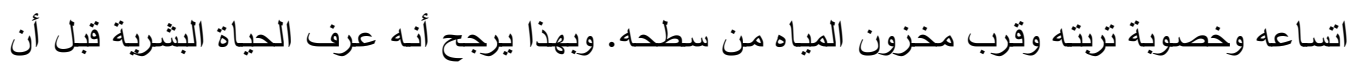
تعرفها المناطق الغربية من اليمن. يقع وادي حضرموت في الجزء الثـرقي للجمهوريـة اليمنية يرتفع الوادي بحوالي(2000 قدم) عن سطح

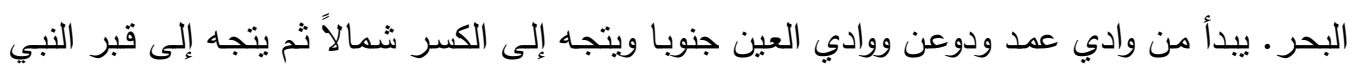

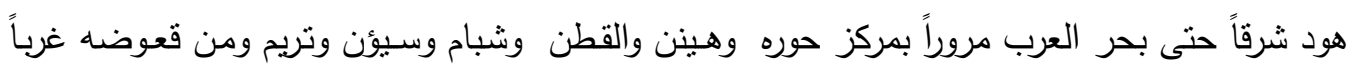

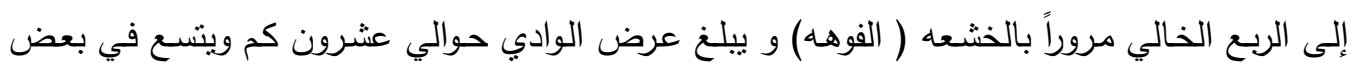

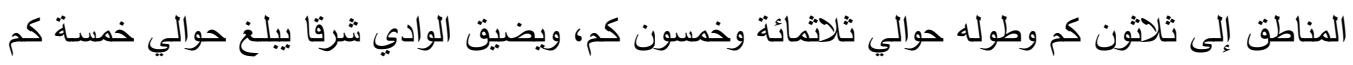
عند مدينة سيئون ويستمر شرقاً ثم يضيق إلى حوالي( 1.5 كم) بعد مدينة تريم حتى المسيلة. ويقع في

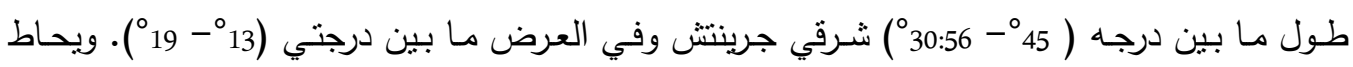

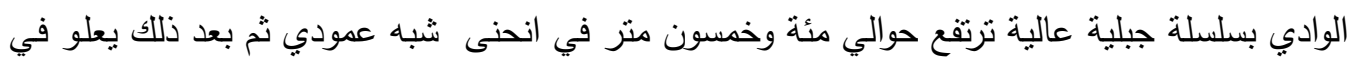
شموخ حوالي مائة وخمسون متر أخرى. يضم وادي حضرموت مدناً ومواقع أثرية و تاريخية تميزت بثرائها وبأبنيتها الفريدة من حيث التصميم

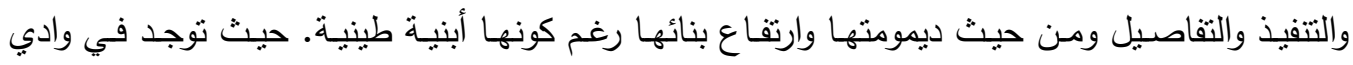

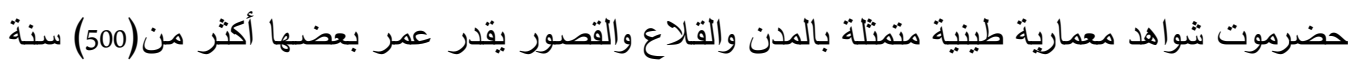

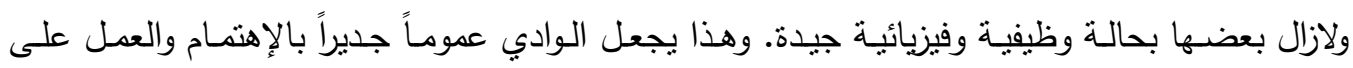

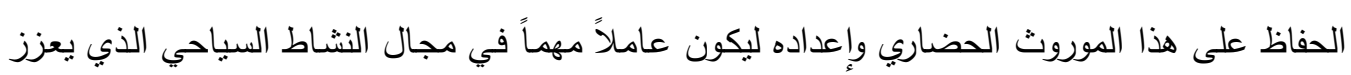

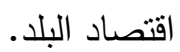


إن منطقـة الدراســة تقـع فـي وادي حضـرموت، أكبـر أوديـة الـيمن وأهمهـا مـن الناحيـة الاقتصـادية

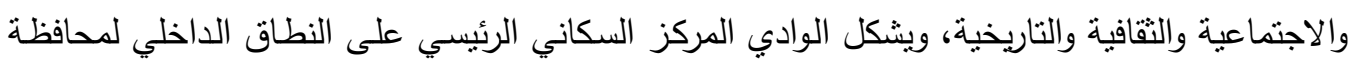

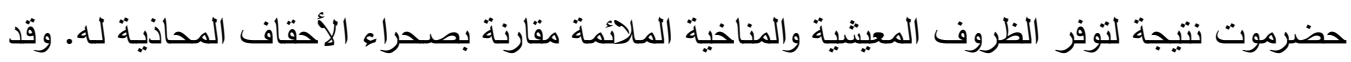
تعاقبت فيه حضارات عدة تاركة إرث حضاري وثقافي عظيمين لا زال جزء لا يستهان به شاهد على تلأك

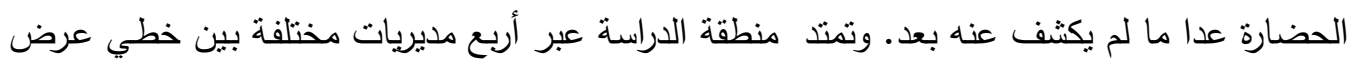

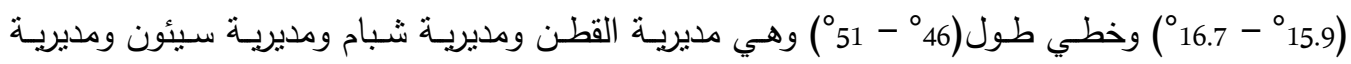
تريم.. هذه المدن التي نثأت وتركبت بها آثار وقصور للحضارات السابقة... والتي تشكل هوية مديزه للوادي وسكانه، والمناطق التاريخية التراثية بحاجة ماسة إلى تطويرها وتحسين بيئتها والإستفادة منها.

\section{2. المشكلة:}

تحتاج المناطق القديمة والتاريخيـة الترانية إلى الإهتمام والمعالجـة البيئية والوظيفيـة لها وجعلها مناسبة

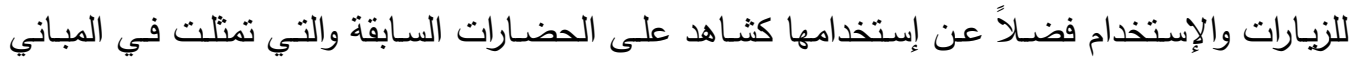

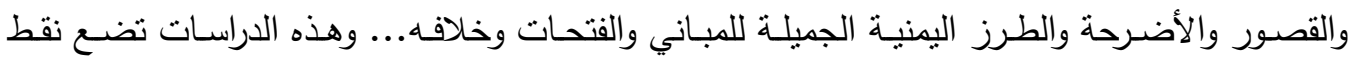

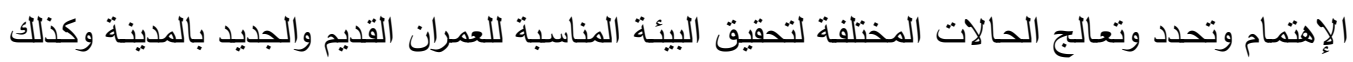
للزيارات السياحية لهذه المدن.

\section{3. الهدف من البحث:}

دراسة الوضـع الراهن لبعض المناطق بهذه المدن وإبراز الأهمية التاريخية والتراثية والمعمارية والطرز

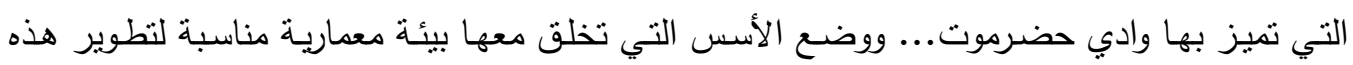
المناطق.

\section{أولاً: مدن وادي حضرموت:}

مدن وادي حضرموت وهي سيؤن وتريم وشبام والقطن بها مناطق تاريخية قديمة تحوي على عناصر

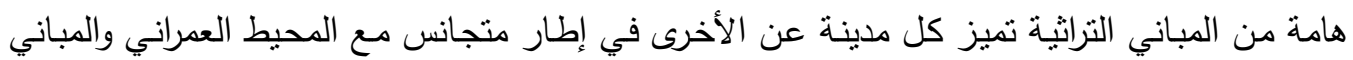

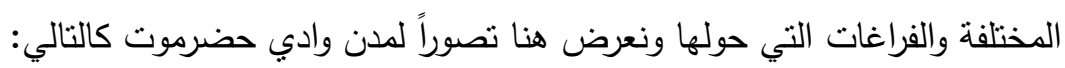
أ- مدينة سيئون:

وتقع في موقع وسطي بين مدن الوادي الرئيسية حيث تبعد (34كم) عن مدينة تريم و (20كم) عن مدينة شبام وهي المقر الإداري وعاصمة الوادي والداخل.

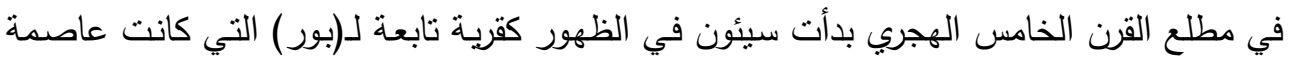
وادي حضرموت آنذاك. 
تشمل مدينة سيئون حالياً عدة مناطق منها مدينة سيئون والغرفة والحوطة وبور وتاربة وغيرها من

$$
\text { القرى والمستوطنات المعمارية، }
$$

أهم المناطق الأثرية في مدينة سيئون هي قصر سيئون و قصر السلطان الكثيري والمنطقة المحيطة به. وبوابة سيئون الغربية على حدود مدينة سيئون القديمة. وتم الإثـارة إلى وجود بعض المساجد

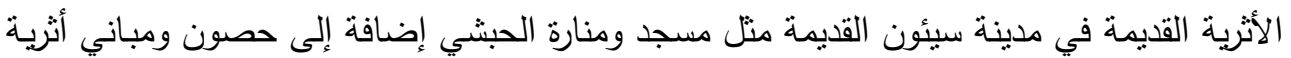
متهدمة كحصن الفلس حول مدينة سيئون وقصور تاريخية داخل مدينة سيئون. في منطقة مريمة هناك بعض الآثار المندرسة في أعلى التل. انظر الأثكال أرقام (3,2,1).

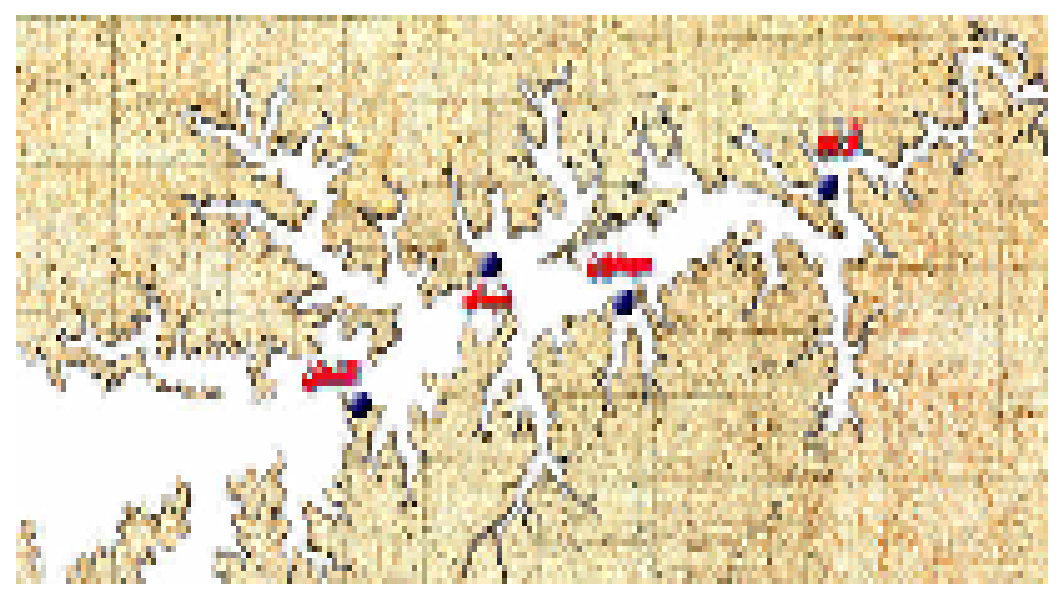

\section{شكل رقم (1) يوضح مدن وادي حضرموت}

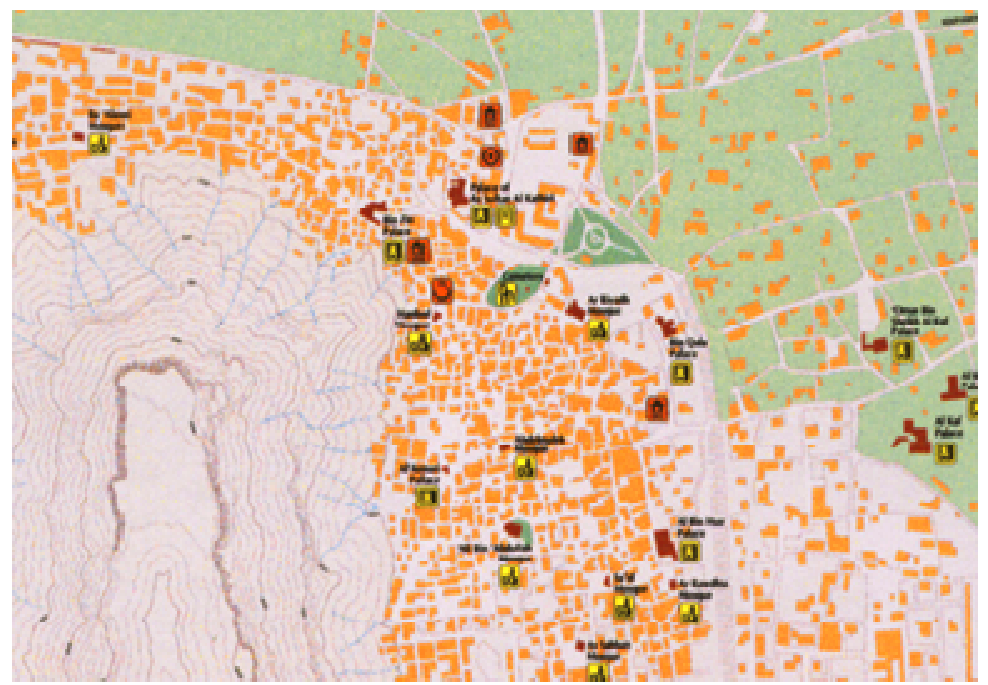

شكل رقم(2) يوضح خريطة مدينة سيئون عليها المواقع التراثية 


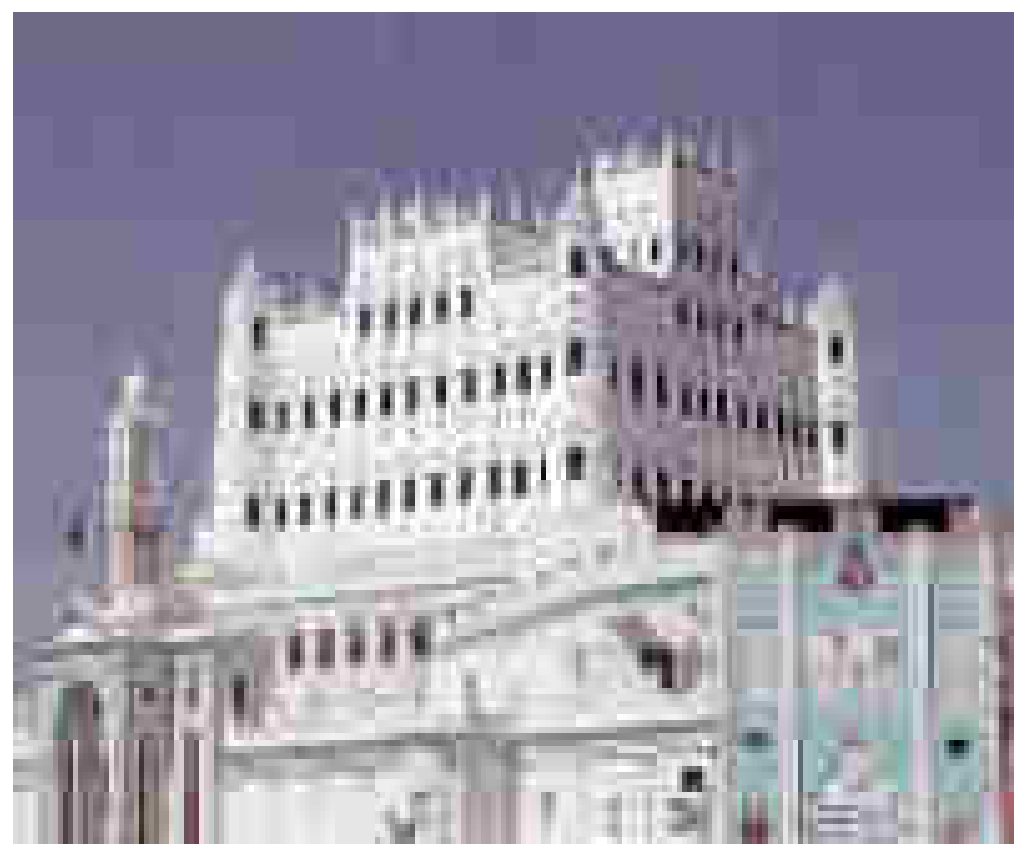

شكل رقم (3) يوضح قصر سيئون

ب- مدينة تريم:

تقع المدينة إلى شرق سيئون وتبعد عنها كما سبق ذكره بمسافة 34كم وتقع على خط عرض16ه

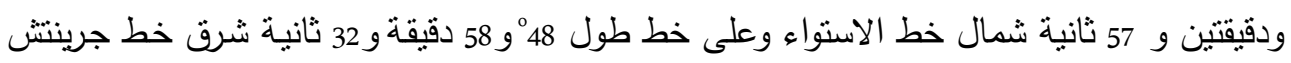

$$
\text { شكل رقم (5،4). }
$$

مدينة تريم القديمة كانت تتكون من حارتين هي الخليف والأزرة متصلتان بحصن الزناد والسوق النجدية الواقعة حول الحصن.

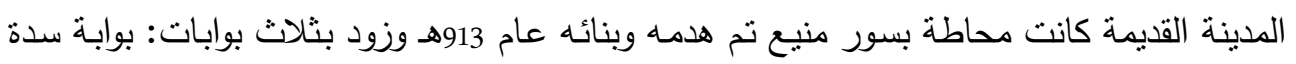
يادين في الجنوب والثانية في الجنوب والثالثة من جهة الثمال. تعتبر مدينة تريم القديمة تاريخية وتعتبر كل الحصون والقلاع المرتبطة بسور الددينة أو خارجها آثنار.

تتشتهر مدينة تريم بقصورها الطينية الرائعة ذات الزخارف والنقوش والتي تجمع بين الطراز العربي

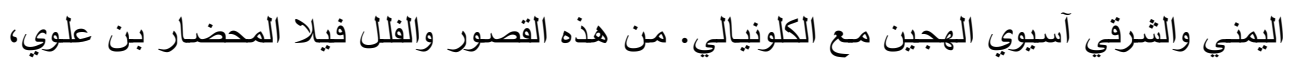

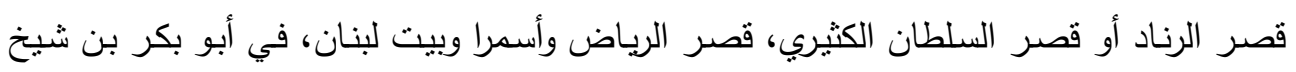

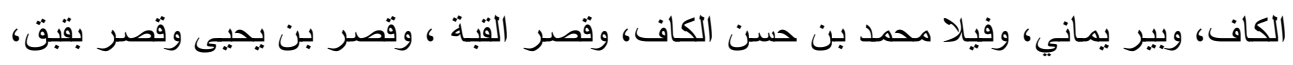

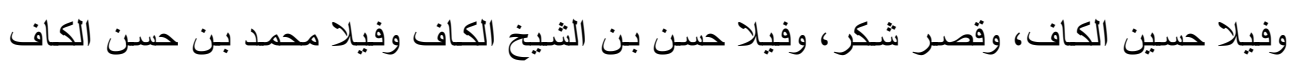


وفيلاعبد القادر بن الثيخ، وفيلا عبد الرحمن بن الكاف، وقصر التواهي، وفيلا عمر بن شيخ

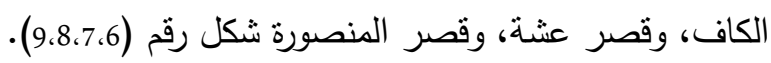
تشتهر مدينة تريم بكثرة مساجدها وكان عددها يقارب الـ 360 مسجداً.

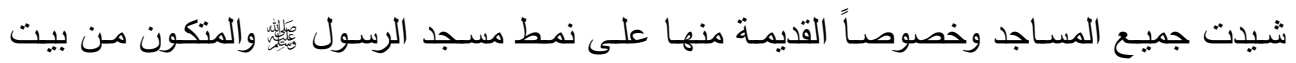
الصلاة الذي ينقسم إلى قسمين مغلق ومفتوح وصحن وحمامات. المساجد المندثرة 14 مسجداً تقريباً. أنظر الشكل رقم (10).

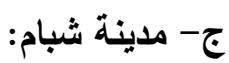

تتسب شبام إلى بانيها الحميري شبام بن الحارث بن حضرموت الأصغر وكانت من المدن المعروفة

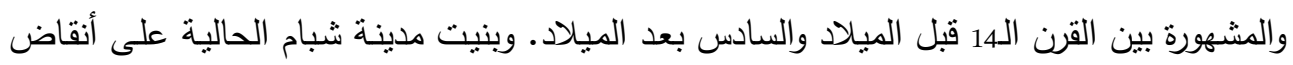
مدينة شبام القديمة مما أعطاها مظهر البناء على قاعدة وكانت محاطة بسور من الطابوق الطيني بارتفاع 5-9وم ويقطع السور ببوابة واحدة من الجهة الجنوبية وهي تتصل مباشرة بفناء كبير .

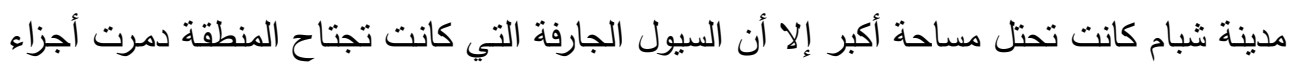

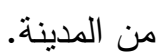

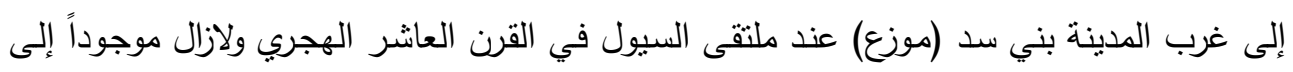

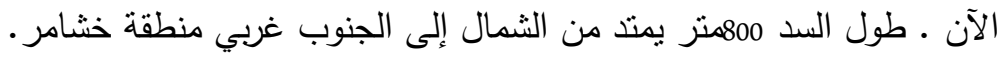

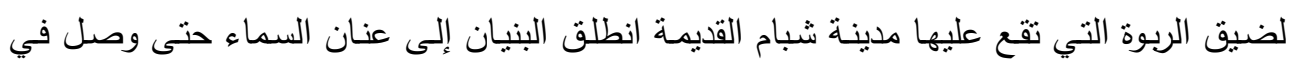

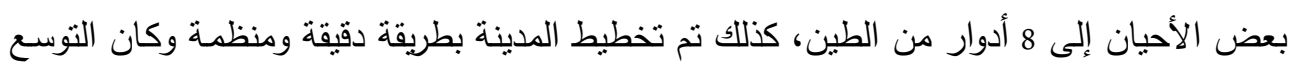
العمودي نتيجة حتمية.

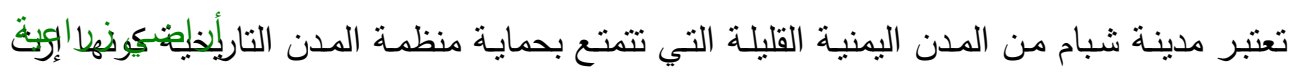
حضاري وعاصمة حضارية قديمة ذات بعد تاريخي وقد حافظت المدينة على نمط الحياة القديمة

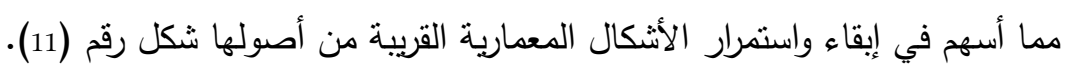

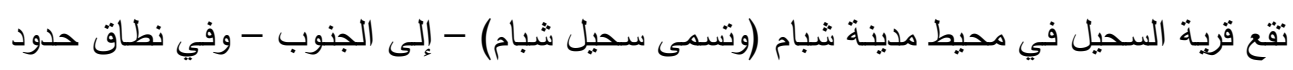
حمايتها. تطل على قرية السحيل مجموعة من الحصون والقلاع التاريخية شيدت على جبل السحيل مثل كوت السعيدية وكوت السلطان بن مهدي أنثكال رقم (14،13،12). 


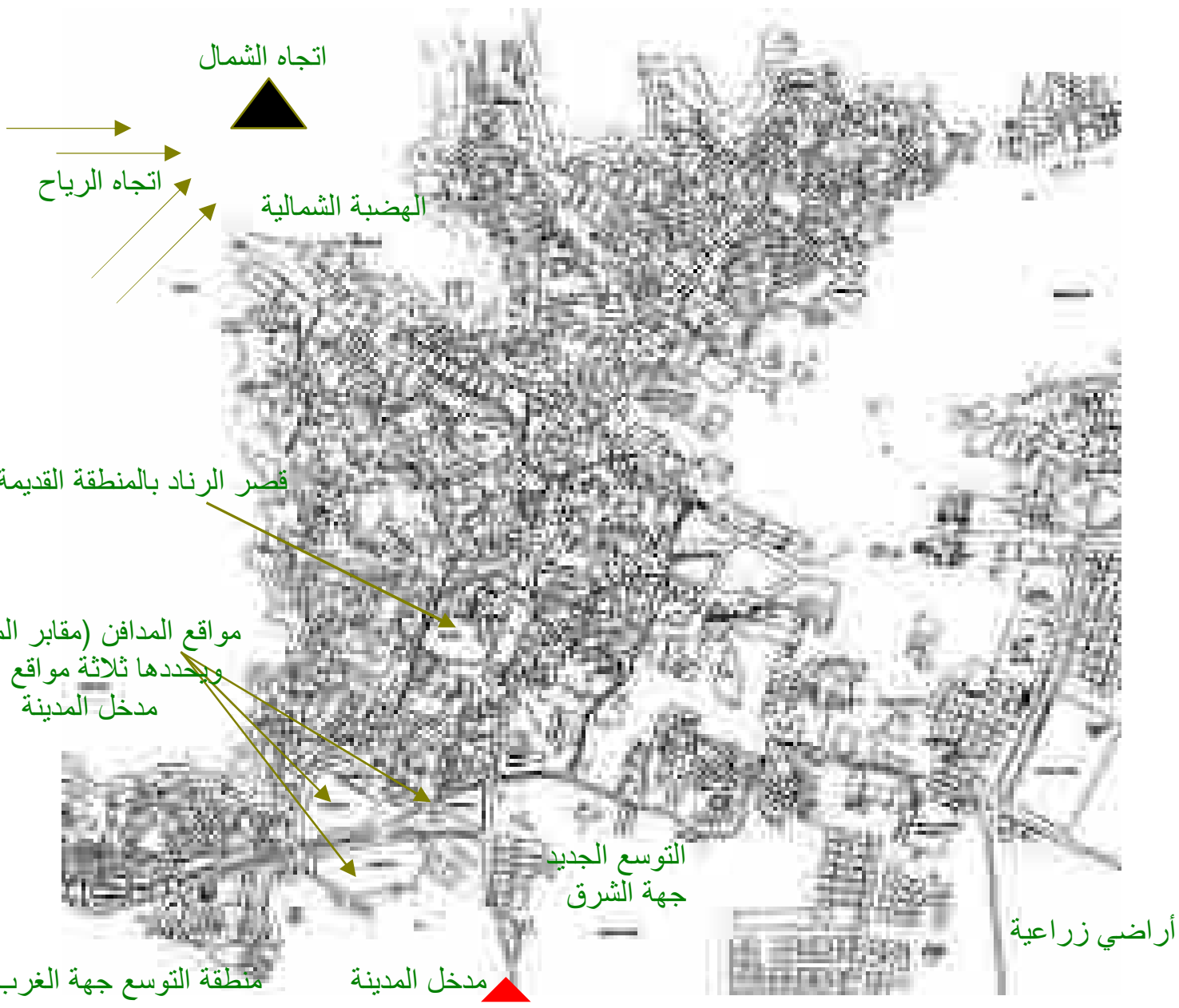

مواقع المدافن (مقابر المونى)

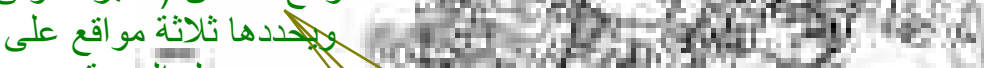

مدخل المدين 

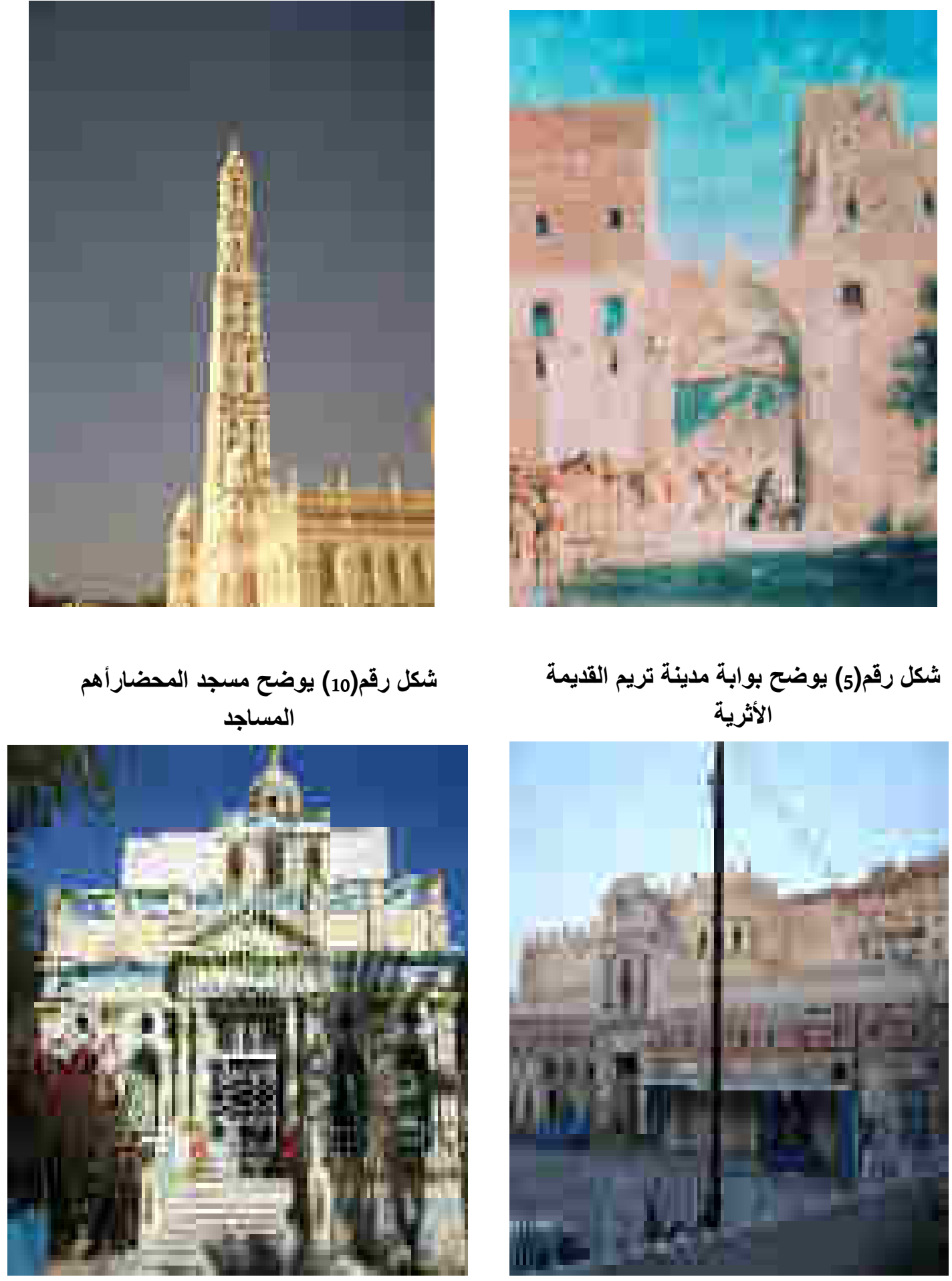

شكل رقم (7) يوضح قصر القبة

شكل رقم (6) يوضح قصر الرناد 


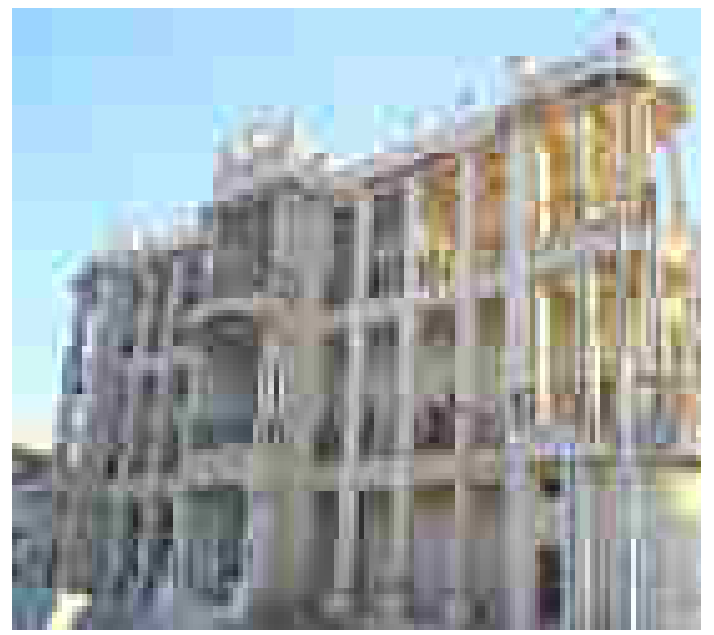

شكل رقم (9) يوضح قصر دار السلام

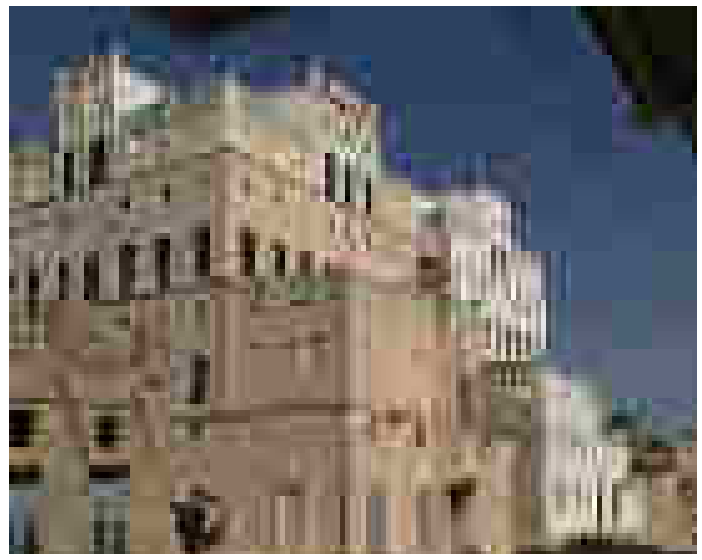

شكل رقم(12) يوضح مباني سحيل شبام

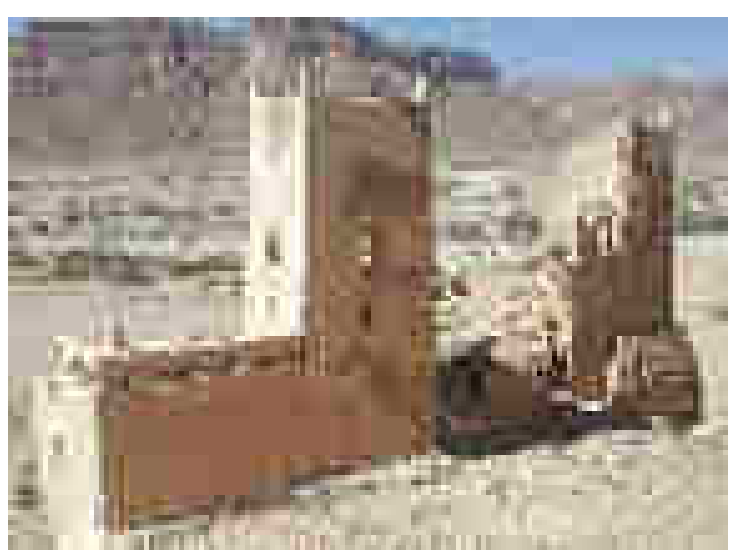

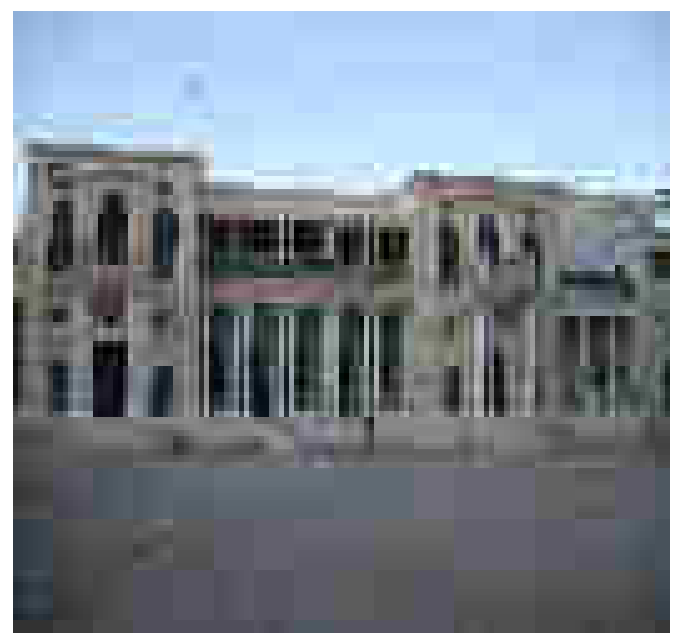

شكل رقم (8) يوضح قصر التواهي

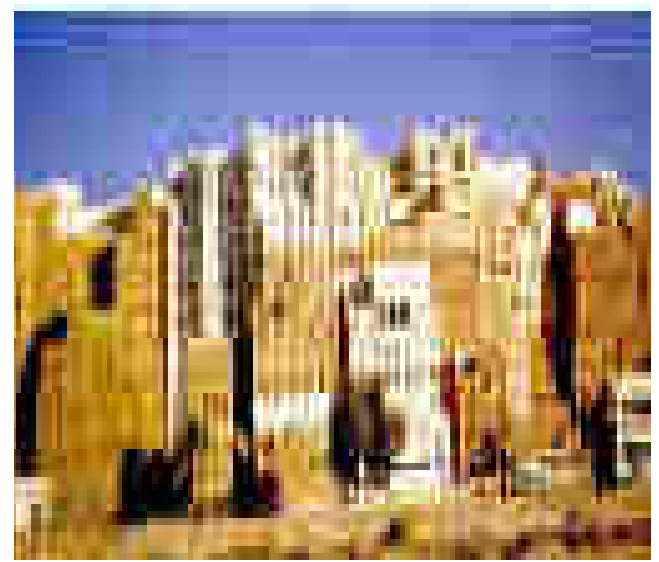

شكل رقم(11) يوضح مباني شبام التاريخية

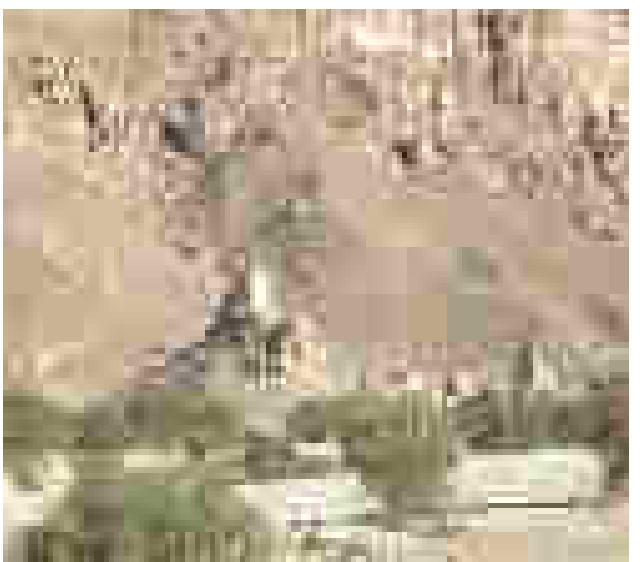

شكل رقم(14،13) يوضح بعض حصون وقلاع مدينة شبام التاريخية 
د - مدينة القطن:

تقع مدينة القطن عاصمة المديريـة غرب منطقة الدراسـة على خط عرض ( 15.8 مُ ) وخط طول (48.5 ) وتقع غرب مدينة شبام.

تتكون المدينة من قرى ومستوطنات متتاثرة.

الجزء القديم من المدينة شكل رقم (15) بنسيجه المتضام تاريخياً كان محاطاً بسور هدم الجزء الأكبر

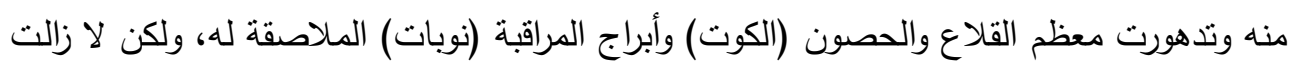
بعض الثواهد باقية.

لا توجد إحصـائية دقيقة حول عدد المستوطنات والقرى والمباني والمواقع التاريخيـة والأثريـة في المدينة وخارجها إلا إن عددها بالعشرات.

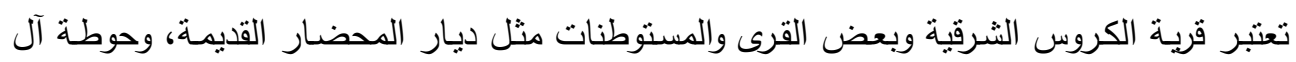

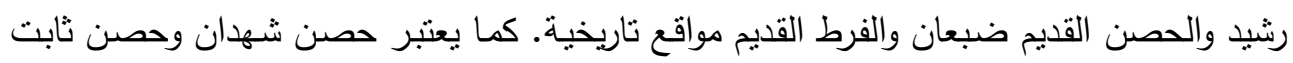
وقصر القعيطي إضافة إلى عدد كبير من الحصون والقلاع أبنية أثرية.

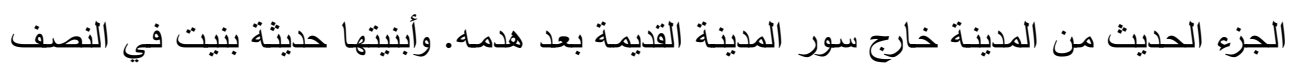

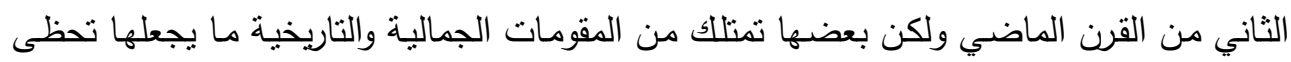
بالاهتمام وبضرورة الحفاظ علبها مثل القصور الحمراء وتعتبر قصوراً ناريخية أيضاً أنظر الأتشكال

$$
\text { رقم (7) (19،18،17،16) }
$$

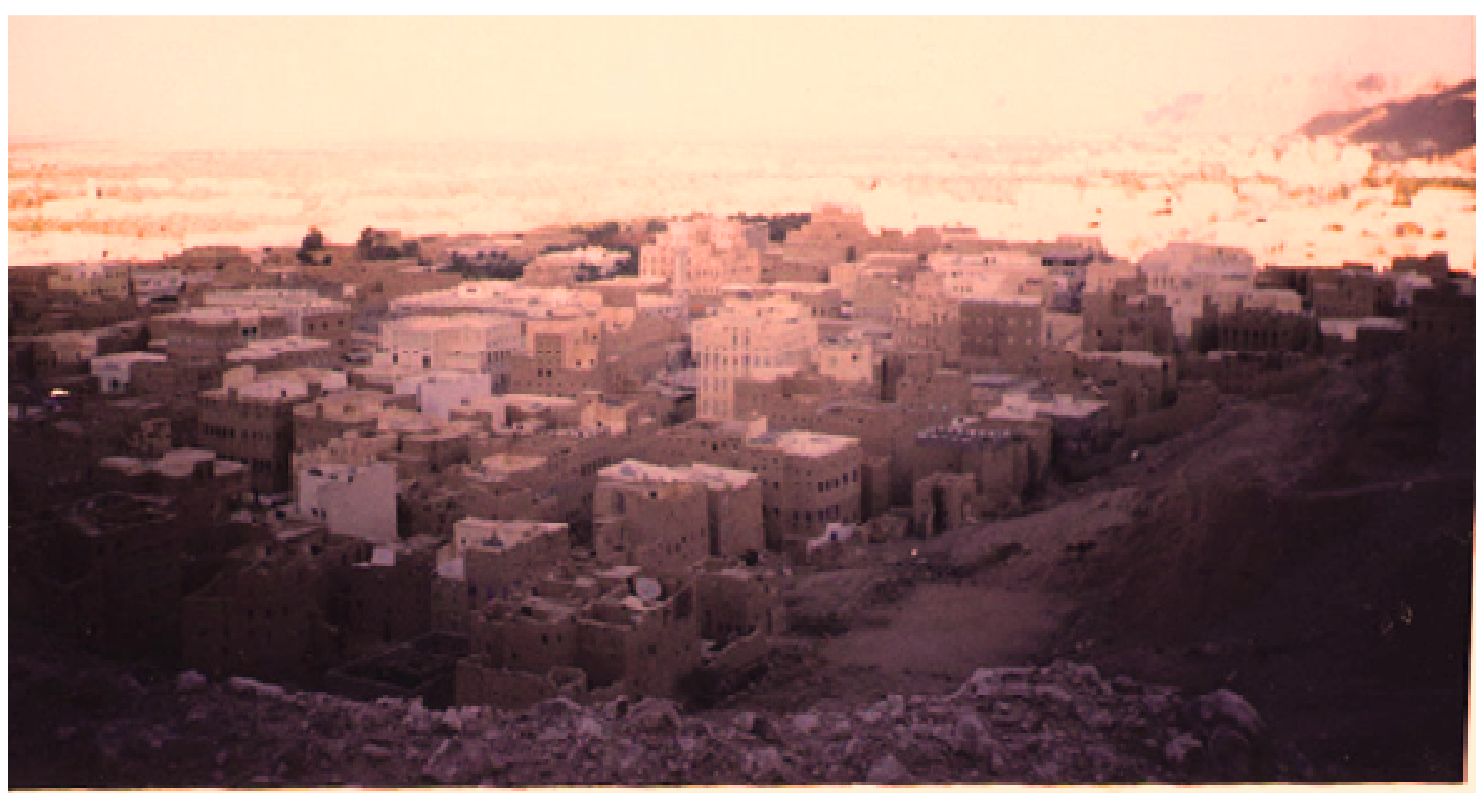

شكل رقم (15) يوضح الجزء القديم من مدينة القطن 

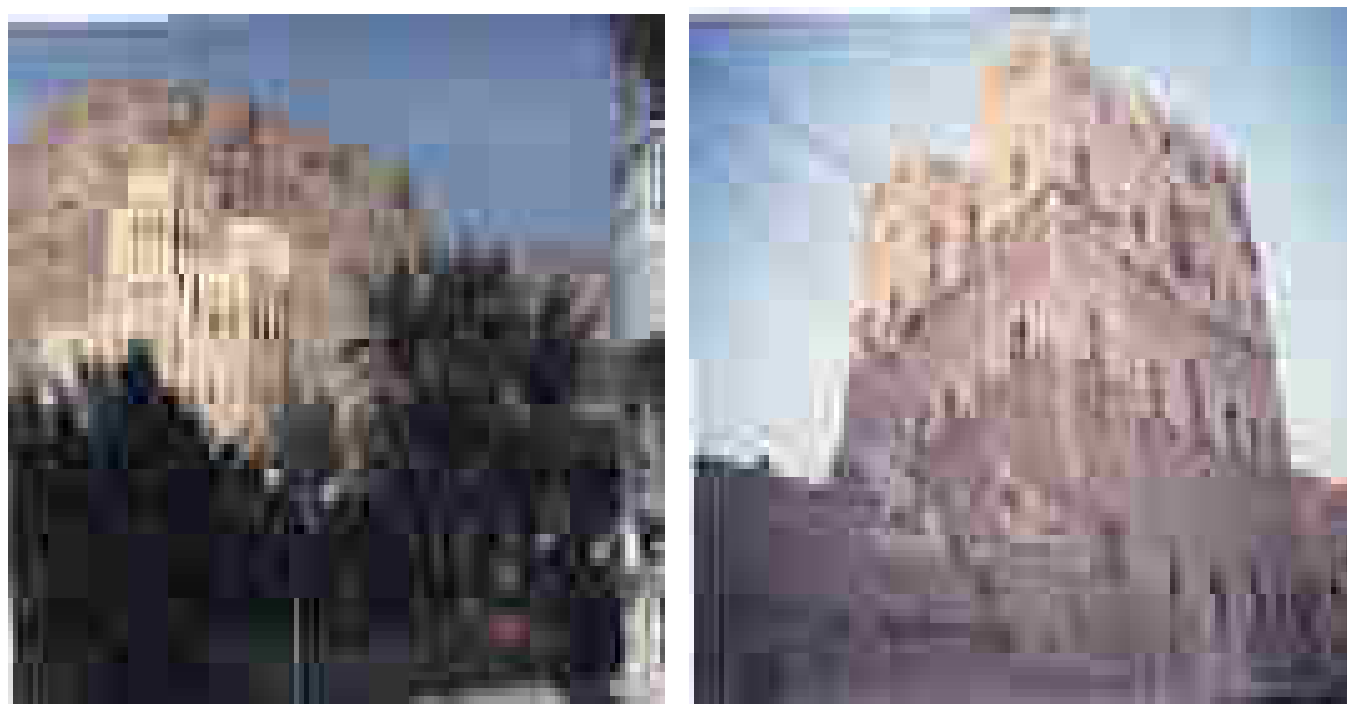

شكل رقم(16) يوضح أحد قصور القطن شكل رقم(17) يوضح قصر السلطان القعيطي و الذي

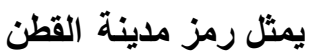
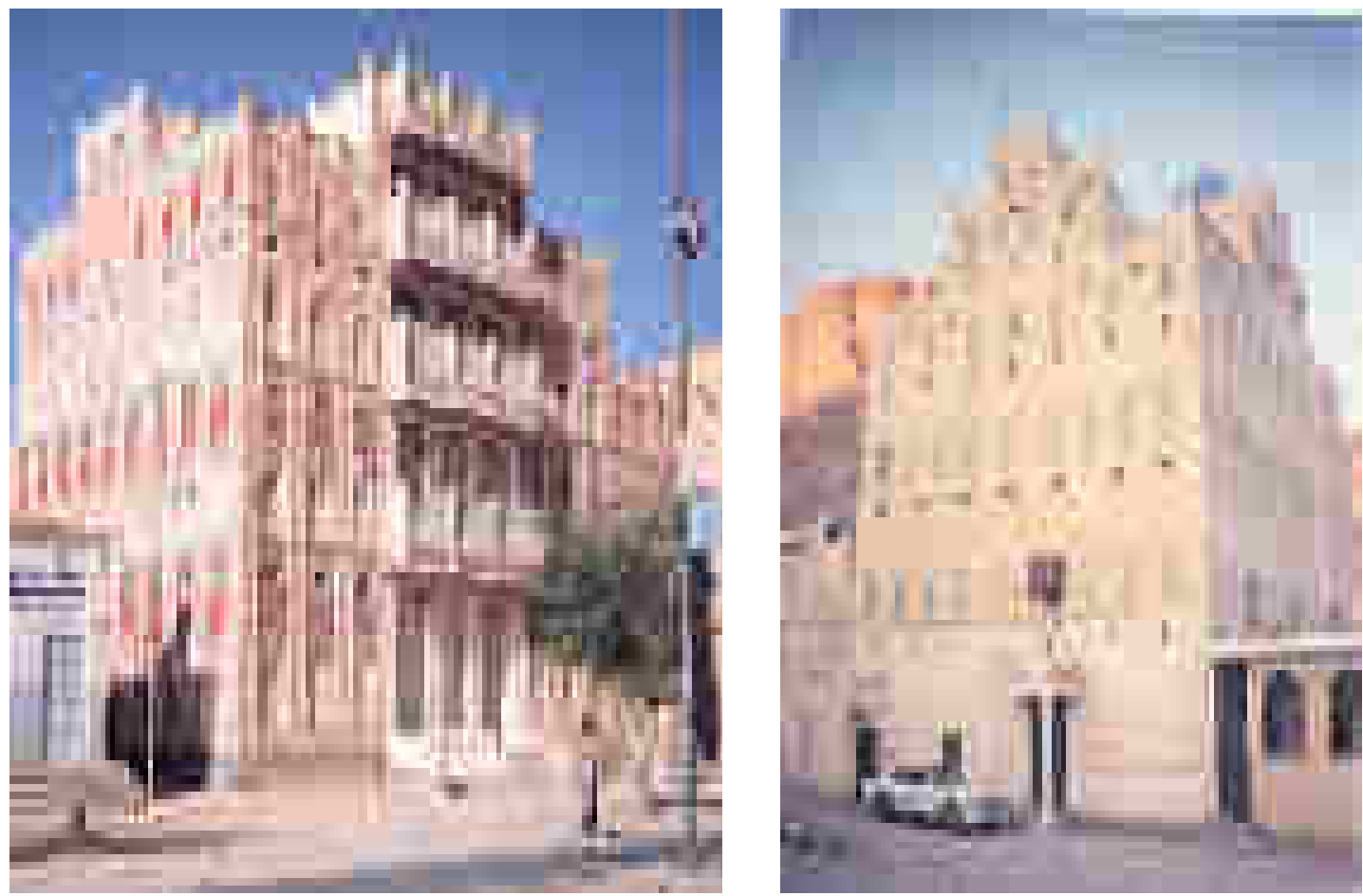

شكل رقم(19) يوضح القصر الأحمر

شكل رقم(18) يوضح القصر الأبيض 
2

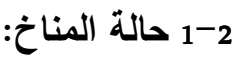

للمناخ تأثير على العمارة وذللك في كافة أنواع المنثآت وخاصة السكنية منها والتراثية وهذا البحث يحاول

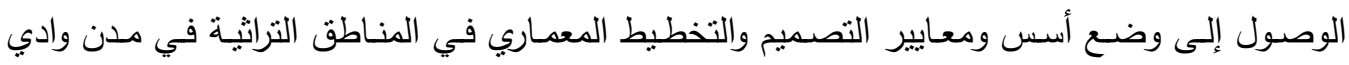

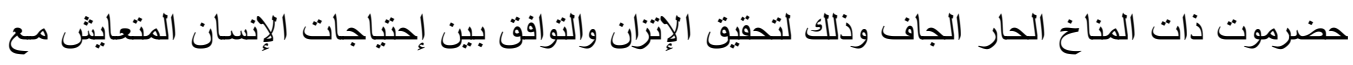
ظروف البيئة وتنطوير المناطق الترانبه في مدن وادي حضرموت . .

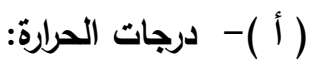

تتميز درجات الحرارة بالإرتفاع العام في نصف السنة الصيفية إذ وصل منوسطها إلى 31.2 درجه مئوية، و الانخفاض النسبي في درجات الحرارة في نصف السنة الثنتوي إذ وصل منوسطها إلى نحو 21.9 درجه

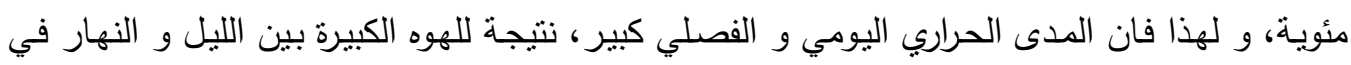
درجات الحرارة و كذلك بين الصيف و الثتاء حيث إن أعلى منوسط درجة حرارة سجلت في سيئون 43 درجه مئوية في شهر يوليو و أدنى منوسط درجة حرارة 9.4 درجه مئوية في شهر يناير .

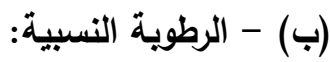

يبلتخ المعدل السنوي للرطوبـة النسبية في الجو 41.4\% مقارنـة بـالإقليم السـاحلي الذي لا يقل منوسط

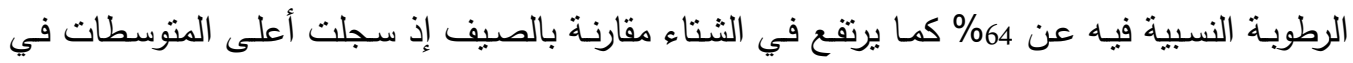

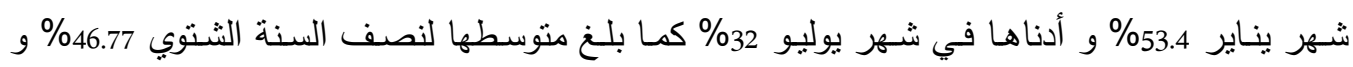
متوسطها لنصف السنة الصيفي 36.1\% و يعزى ذلك التباين إلى الاختلاف في معدلات درجات الحرارة من جهة و إلى التباين في سرعة الرياح بين هذين الفصلين من جهة أخرى.

$$
\text { (ج) - الرياح: }
$$

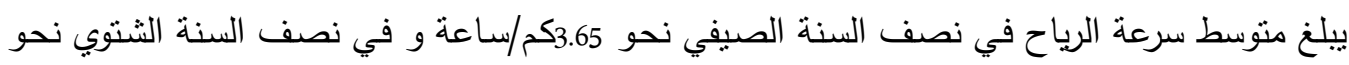

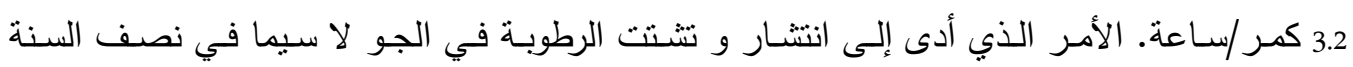

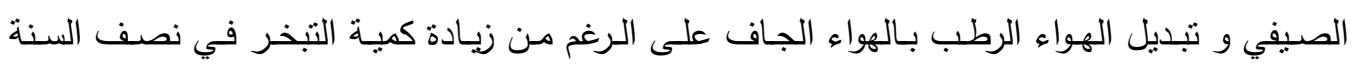

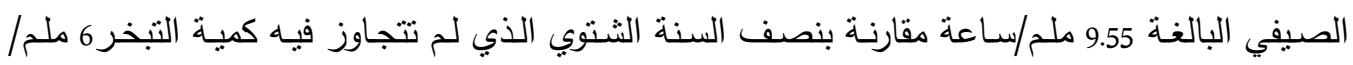

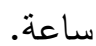

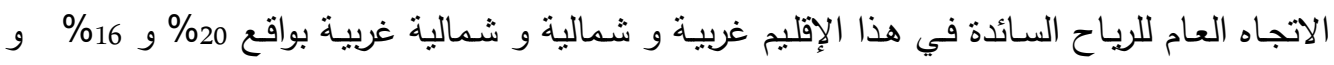

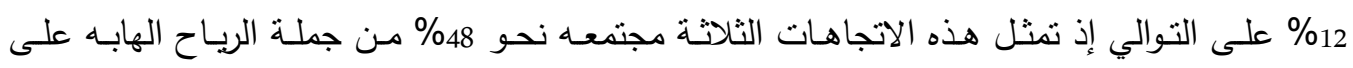
الإقليم[4]. 
إن للثمس أثر كبير في حياة الإنسان ولهذا فلها تأثير مباشر على العمارة، وكما أن الإنسان يحمي نفسه

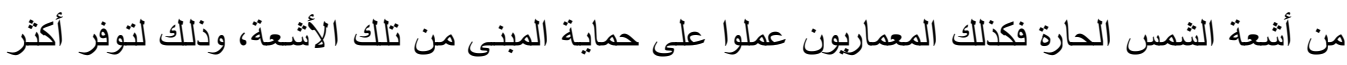
سبل الراحة لهذا الإنسان. 2-2-2-2 كاسرات الثمس: وهي عبارة عن عناصر تتشأ خصيصا للوقاية من أشعة الثمس وتتخذ عادة أحد اتجاهين الرأسي أو الأفقي أو كليهما معا، وفيما يلي أهم مميزات كل نوع من الأنواع الثثلاثة الرئيسية التظليل الأفقية والعمودية كذلك والأفقية. الأنواع الأفقية ( Horizontal Types)؛ 1. يفضل استخدام الثرائح الأفقية في الجهة الجنوبية أو حول هذه الجهة.

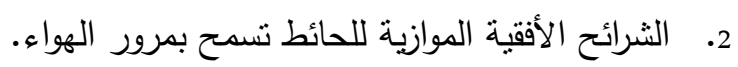

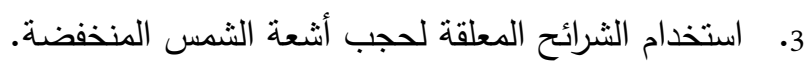
4. الثرائح الأفقية المتحركة يتغير مسقط ظلها حسب الحاجة. الأنواع الرأسية(Vertical Types):

1. يفضل استخدام الثرائح الرأسية العمودية في الواجهات الثرقية والغربية والثمالية.

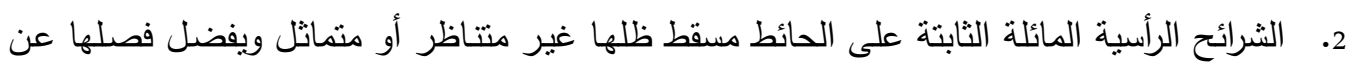
الحائط حتى لا تتنقل الحرارة بالحمل إلى غلاف المانس المبنى. 3. الشرائح الرأسية المتحركة يمكنها نظليل كامل مساحة الحائط ويمكن توجيهـا إلى أي اتجاه معاكس أو باتجاه الثمس حسب فصول السنة.

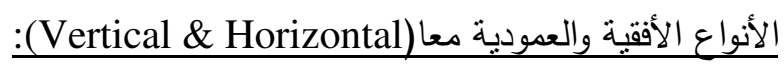
1. الثرائح العمودية والأفقية الثابتة هي عبارة عن مجموع مسقطي الظل للثرائح العموديـة والثرائح الأفقية وتتاسب أي اتجاه جغرافي.

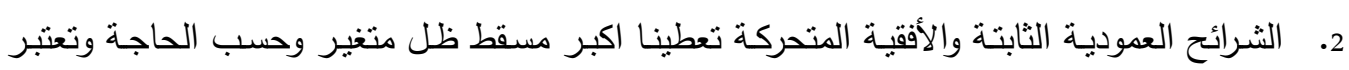
أفضل وسائل كاسرات الثمس وخاصة في المناطق الحارة شكل رقم (20) [2].

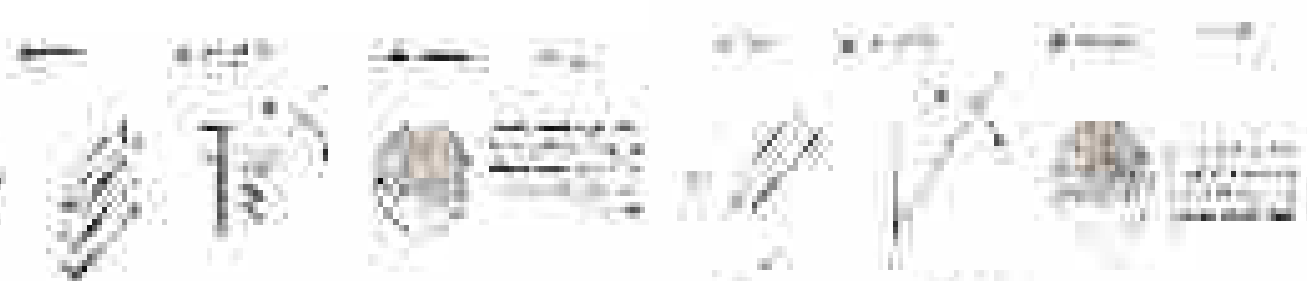


شكل رقم (20) يوضح بعض أنواع كاسرات الشمس

:2-2

هي عبارة عن فتحات قد تكون على شكل كتل بارزة فتسمى (الشناشيل) أو فتحات في الجدران مباشرة فتسمى (المشربيات). تكون ذات أشكال هندسية ومغلقة بقواطع وذات وظائف متعددة منها: 1. السيطرة على كمية الضوء الداخلة إلى الفضاء الداخلي للمبنى.

2. تقليل درجة حرارة الهواء الجاري ( باستعمال معالجات خاصة مثل : جرار ماء او نباتات زكية). 3. زيادة الرطوبة النسبية للهواء ( المعالجات السابقة ). 4. تحقيق الخصوصية. 5. توفير التظليل بواجهات المباني. وتكون المشربيات على أثكال أبراج بارزة من الخشب المحمول على حوامل خثبية مكونة من عدة ألواح مملوءة بمخرمات خثبية بعضها ثابت وبعضها متحرك، وقد توجد أيضا تلك المخرمات في أرضية برجها البارز في الهواء تقابلها ألواح مخرمة في السقف مما يسمح بالتخلل إلى هذه الشناشيل رأسيا من الأسفل بردي إلى الأعلى وأفقيا من الجوانب. 


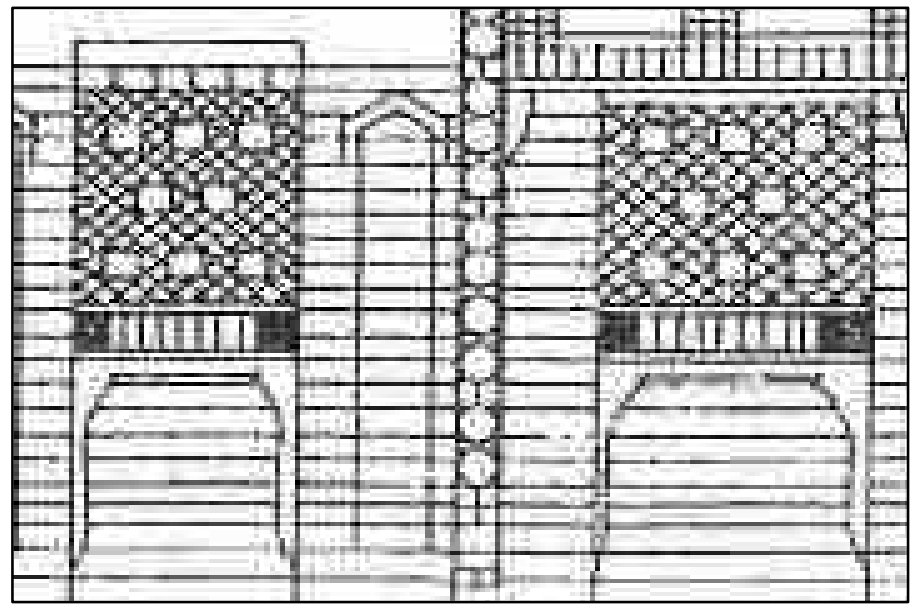

شكل رقم (21) يوضح نموذج لبعض المشربيات التي ظهرت في مدينة الهجرين بوادي حضرموت

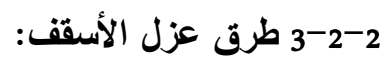
تعتبر السطوح احد الأجزاء الوظيفية المهمة في العمارة التراثية، فهو فضـاء معيثـي يعد أيضـا للنوم

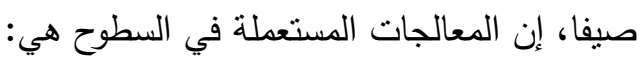

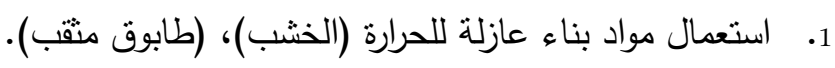

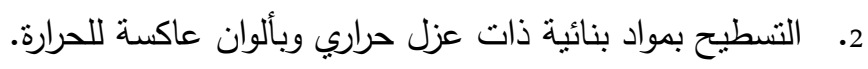

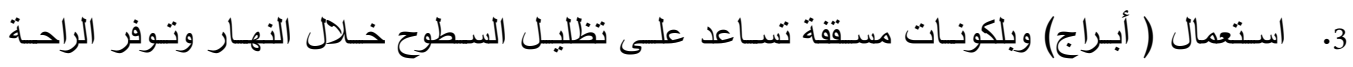
السيكولوجية خـلال الليل. وكأنها طابق آخر غير مسقف وخالي من الفتحات الخارجيـة ويحتوي

$$
\text { بعضا منها مايلي: }
$$

- توفير أماكن بشكل غرف بدون أسقف لكنها منظورة في الخارج يستخدمها الناس في ليالي الصيف. - ارتفاع الستارة عمل على كسر أنعة الثمس وإلقاء ظلال عميقة أثناء النهار فوق أرضية السطوح نفسها ما يقلل كمية الحرارة التي تكسبها السطوح.

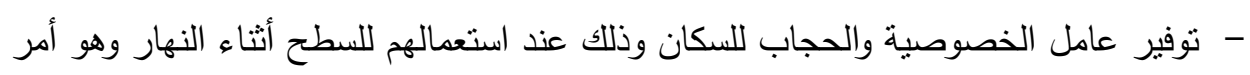
تتطلبه العوامل الدينية والاجتماعية.

2-2-2

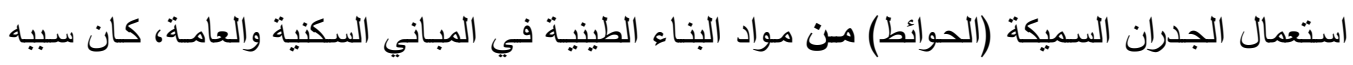
الأساسي إنشائي إلا أنها ساعدت في الاحتفاظ بدرجات الحرارة الداخلية بعيدا عن التقلبات الخارجية في درجة الحرارة[6]. 2-2 طرق عزل أشعة الثمس خارج المباني: 
زراعة المحيط الخارجي وتتسيق وتحديد الممرات وبالتالي امتصاص حرارة الأشعة الساقطة وتثتيتها بعيداً عن المباني. زعة المبط. زراعة الأثجار المورقة دائمة الخضرة مما يؤدي إلى حماية المباني وتظليلها ومنع أكبر قدر من الأشعة عن الحوائط طول فنرات النهار إتجاه وحجم فتحات الثبابيك والتهوية الطبيعية. الفناء الداخلي للمسكن وأهيته في خلق مناخ بيئي مناسب حرارياً يحقق التهوية الطبيعية والنظليل

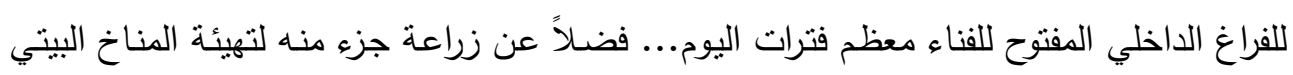
المناسب للرؤية وإنخفاض درجة الحرارة[3].

\section{3- الأثر البيأسي لحالـة المنــاخ على تشـكيل وتخطبط المنـاطق التراثيـة بمـدن وادي حضرموت:}

لقد إستفاد السكان بوادي حضرموت من الموقع الجغرافي والمكاني المتميز لوادي حضرموت ومناخهـ

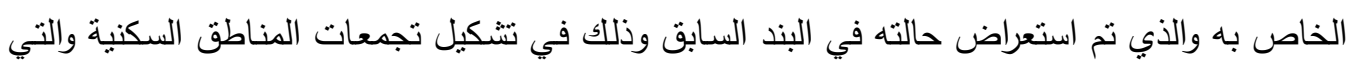
تميزت بعمارتها التاريخية والتراثية لعقود عديدة.

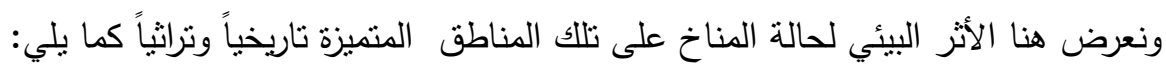

3-1-:تخطيط وتثكيل مباني مدينة شبام التاريخية (تحت إثراف منظمة اليونسكو) : تخطيط الطرق والساحات:

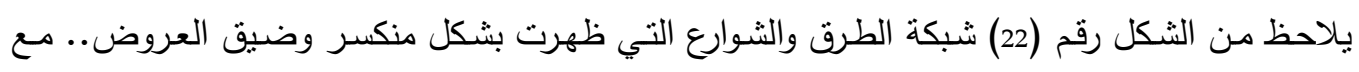

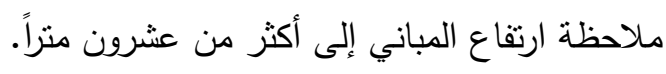

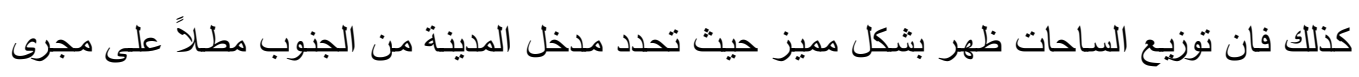

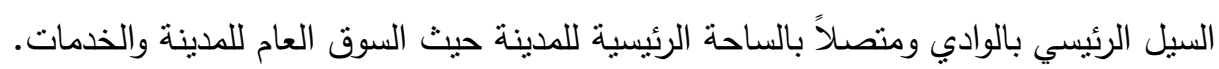

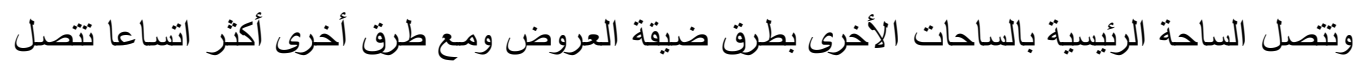

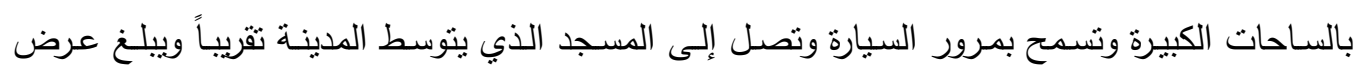
المدينة التاريخية230 منراً طولها 360منراً. 


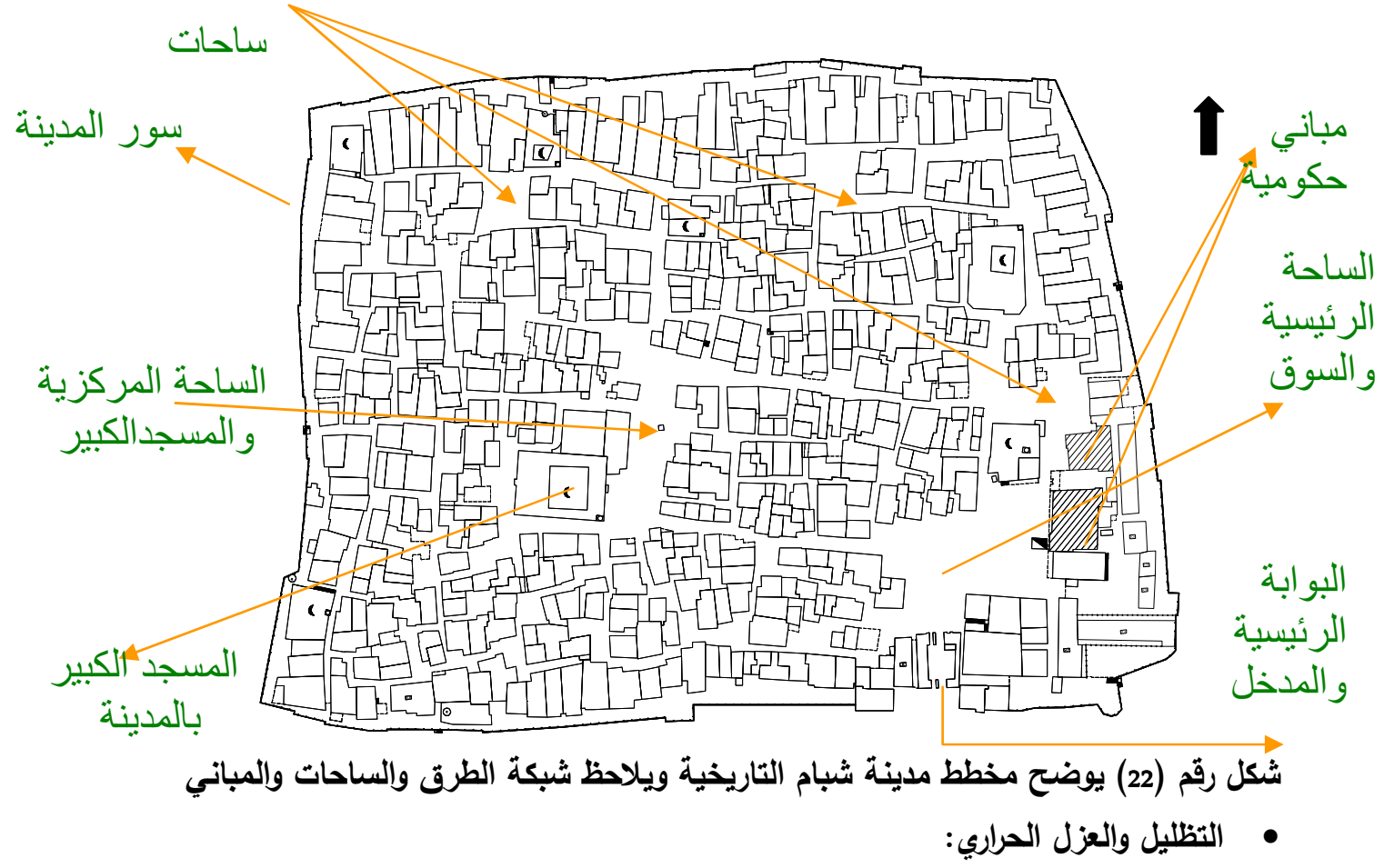

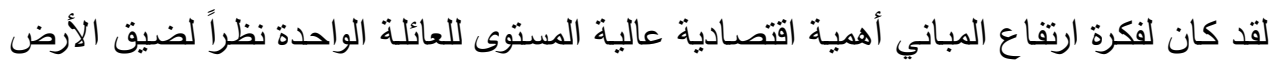

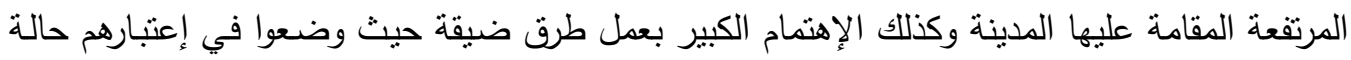

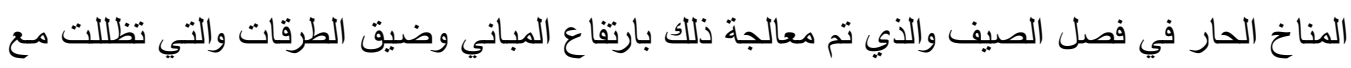

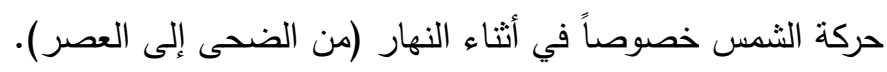
كذلك قد تم مراعاة الحمايـة من الثمس التي تتعرض لهاه المباني ل... فقد تم بناؤها من الطين

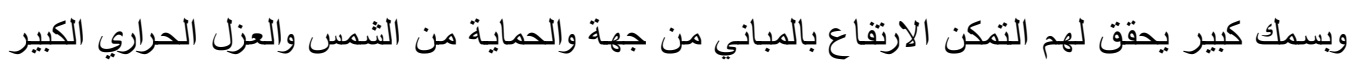
من الحرارة وتحقيق المناخ المريح والمناسب داخل المساكن شكل رقم (23).

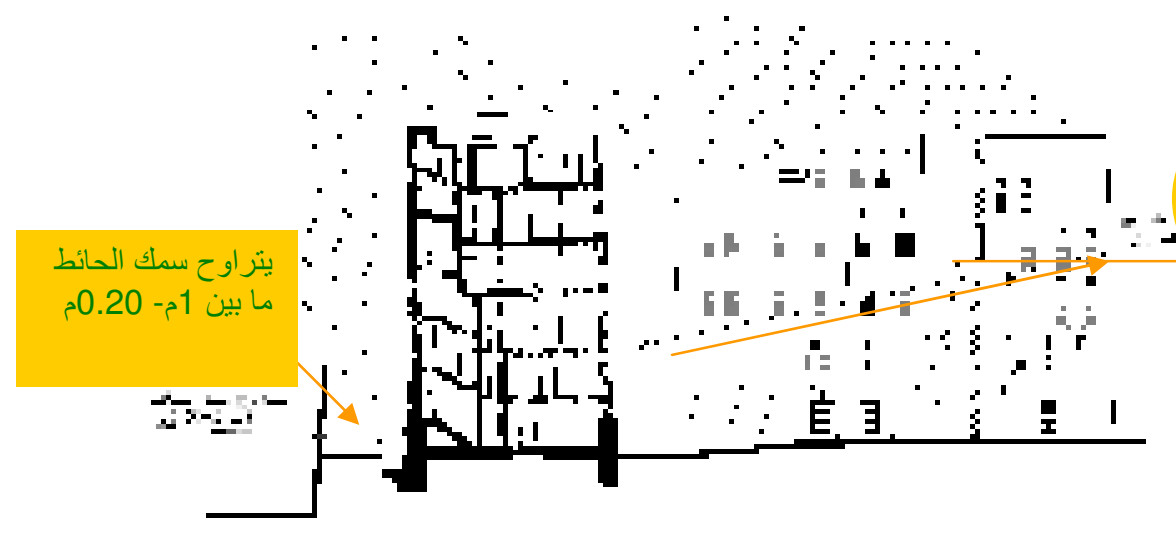

شكل رقم (23) يوضح الثكل إرتفاع المباني وضيق الطرقات بمدينة شبام وتدرج سمك الحوائط 
3-2 منطقة قصر سيئون:

المنطقة التاريخية وموقع القصر:

يقع قصر سيئون على ربوة ترتفع عن المحيط الخارجي بحوالي10 أمتار وفي المنطقة التاريخية

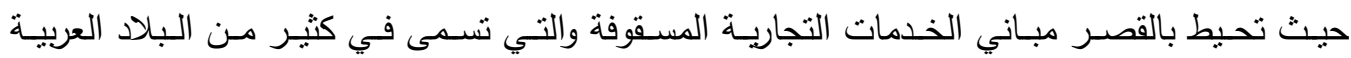
(بالقيسارية) وكذلك المقاهي والمحلات التجارية والمطاعم.

ويلاحظ من المخطط للمنطقة التي يقع بها القصر أنه موجه جهة الثمال والمدخل القصر جهة الثها

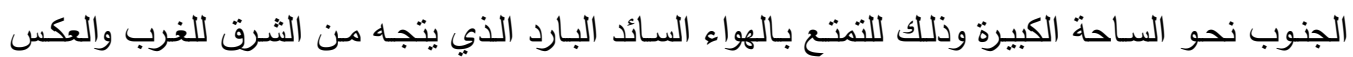
صحيح. أنظر الثكل رقم (24).

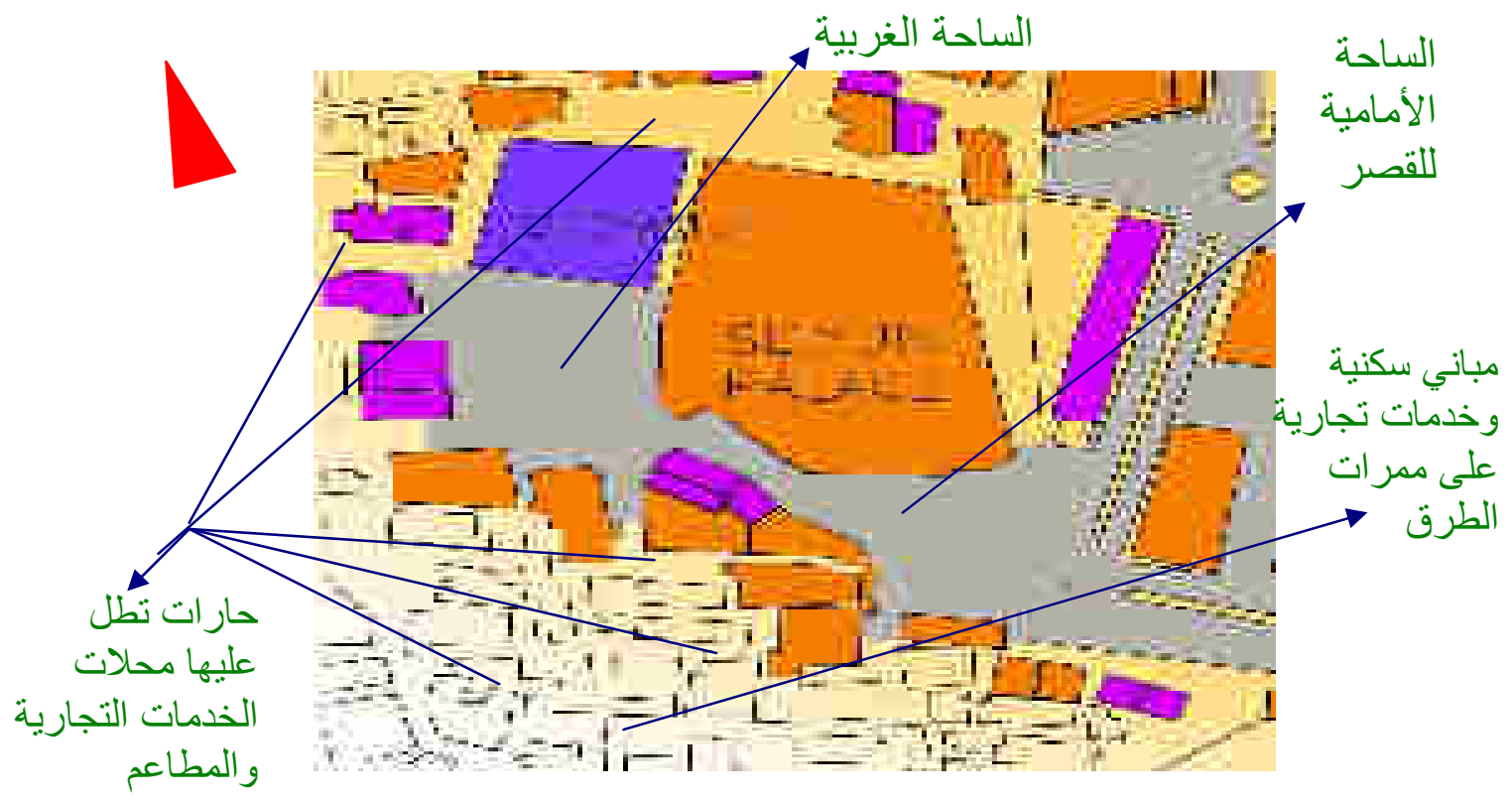

شكل رقم (24) يوضح مخطط منطقة قصر سيئون التاريخية ويلاحظ المساحة الكبيرة الغربية والمساحة الكبيرة أمامه ومواقع مباني الخدمات. التظليل وإلعزل الحراري والتهوية: المنطقة القديمة في مدينة سيئون جاءت تتغلق إلى الداخل وتتحول إلى كتلة كبيرة تتخلاها طرقات ضيقة لكي تتعرض بالحد الأدنى إلى شعاع الثمس البيئة الخارجية. كانت الفكرة الأساسية للتظليل والعزل

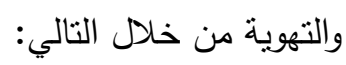

1. استعمال المواد المحلية في البناء و لاسيما الطين و الخشب لما لهما من خاصية العزل الحراري.

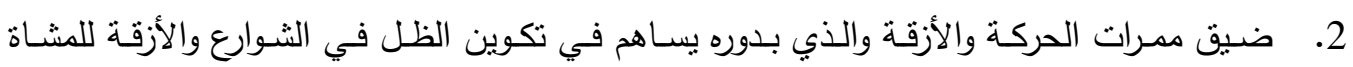
ولواجهات المباني. 
3. استعمال الجدران السميكة من مادة الطين في المباني والذي ساعد على الاحتفاظ بدرجات الحرارة داخليا بشكل متوازن بعيدا عن التقلبات الخارجية لدرجات الحرارة.

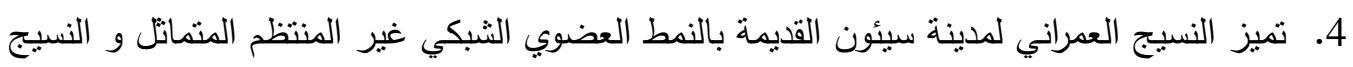

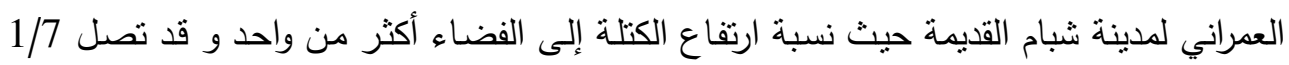

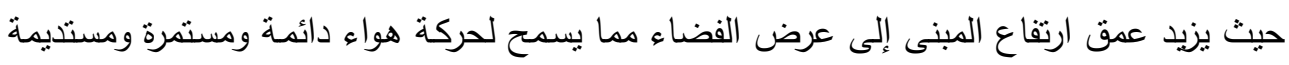

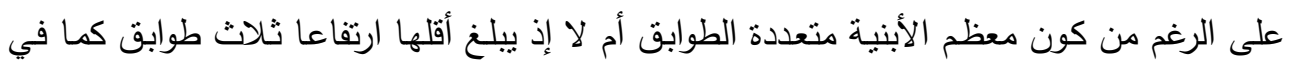

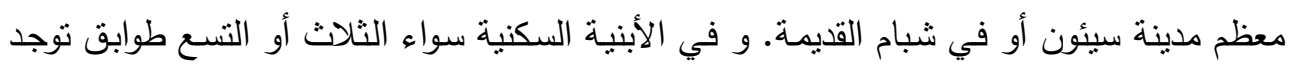

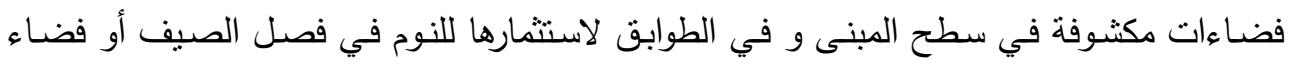
مفتوحا مكملا للوظائف الفضائية بالمبنى التي تستغلها العائلة.

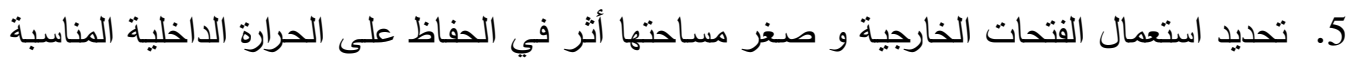

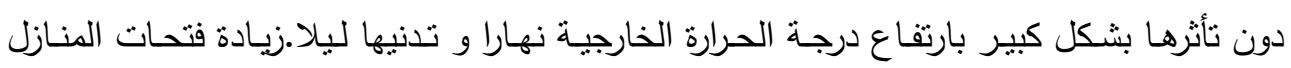
خاصة في اتجاه هبوب الرياح و منصرفها.

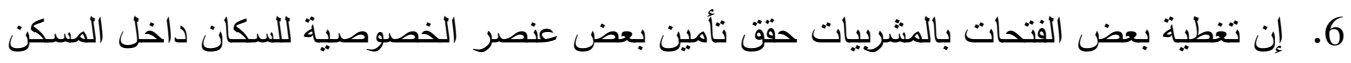

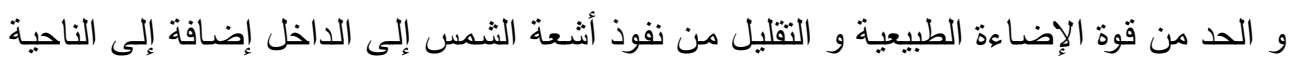
الجمالية التزينية للفتحات.

3-3 المنطقة القديمة والقصور والمقابر بمدينة تريم: يتضح من خريطة المدينة أن مدخل المدينة يتجه من الطريق العام إلى المنطقة القديمة لمدينة تريم والتي ترئي

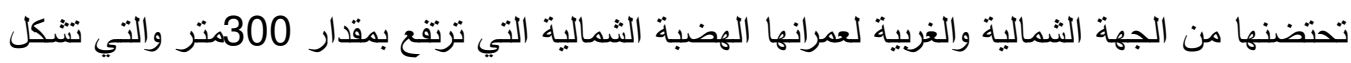

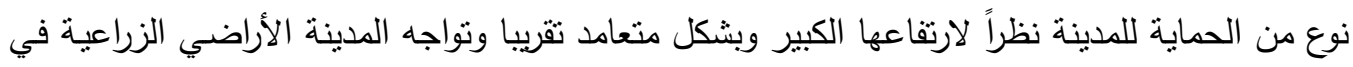
قلب وادي حضرموت حيث تأتي المياه عند سقوط المطار وجريانها نحو البحر العربي بمرورها بين الهضبتين الثمالية والجنوبية والتي تصل إلى منطقة المسيلة حيث مياه البحر وتعتبر مناخ وبيئة تريم جيداً حيث تمر بها الرياح الثرقية والجنوبية الثرقية وتمر على الزراعات والمزارع وتحقق تلطيفاً وتخفيفاً لدرجة الحرارة صيفاً في مبانيها وعمرانها. وتتكون المدينة من عناصر معمارية وتراثية هامة نذكرها فيما يلي:

- القصور الثراثية والمدينة القديمة.

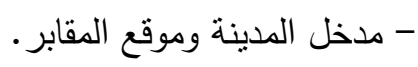

- - - الساحات وبوابة تريم القديمة.

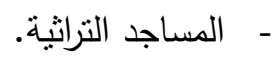

3-3-3 الساحات ويوابة تريم القديمة:

تقع معظم المحلات التجارية في المنطقة القديمة التي تتميز بعمرانها التراثي ونظام الطرقات المعرجة والساحات الواسعة والمحلات التجارية المتلاصقة التي تميزت بها المدن العربية والإسلامية ويتضح من فئن 
الخريطة شكل رقم (4) خريطة المدينة محدداً عليها المنطقة القديمة ومدخل وبوابة المدينة كما يتضح من الخريطة السـاحات والفضـاءات التي تنكل عنصـراً هامـاً من تكوين المنطقة القديمـة والتي تعالج التكس العمراني وتساعد على خلق مناطق التجمع السكاني وكذللك للتهوية وتقع بوابة تريم عند مدخل المدينة وتشكل عنصراً هاماً للمدينة القديمة.

2-3-3 القصورالتراثية والمدينة القديمة:

وتقع القصور التراثية الهامـة بالمنطقة التاريخية للمدينة وتقع في إتجاه المدخل الرئيسي للمدينة وبوابة

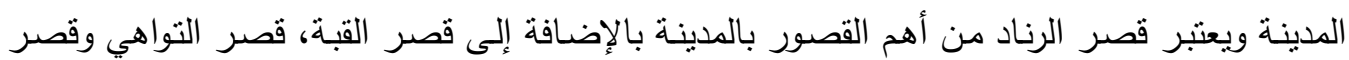

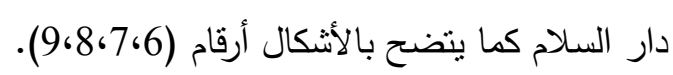
3-3-3 المساجد التراثية:

ويعتبر مسجد المحضار علامة مميزة لمدينة تريم بتصميمها الرائع ومئنته الفريدة في تصميمها ومبني

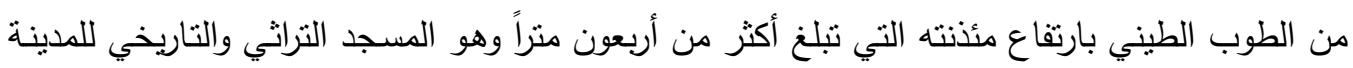

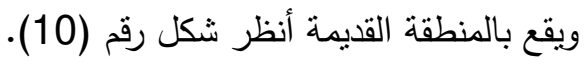
3-3-3 مدخل المدينة وموقع المقابر:

وتقع منطقة الجبانات والمدافن التي تحتوي على مقابر الموتى في مدخل المدينة الرئيسي جهة اليسار

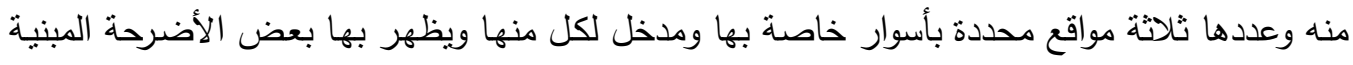
وتتضح مواقعها من خريطة المدينة شكل رقم (4). 3-3-3 توجية المباني والمحيط العمراني المؤثر مناخياً:

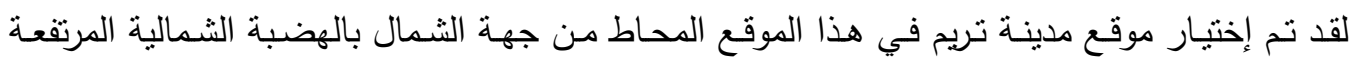
للحمايـة والذي يؤكد ذلك سور المدينة الممتد من مدخل المدينـة جنوب المدينـة والمتجـه شرقاً موازياً

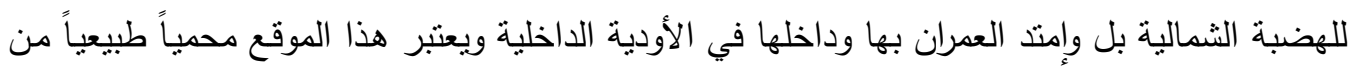

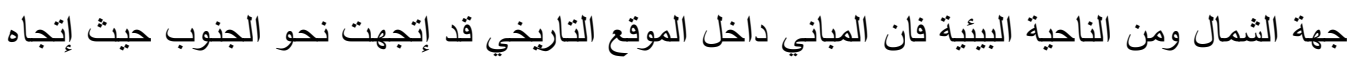

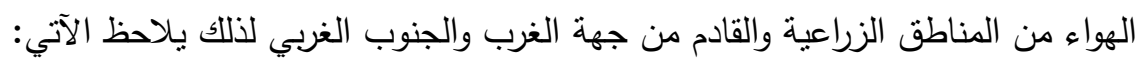
إنجاه المباني جهة الثرق والجنوب لإسنقبال الهواء. إتجاه الطرق الرئيسية جهة الثرق وجهة الثمال في المنطقة التاريخية وقد تم إنباع ذلك في مناطق لإنقاه

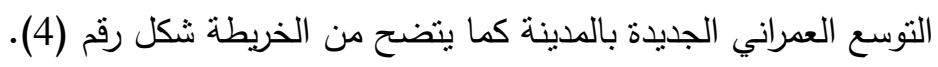

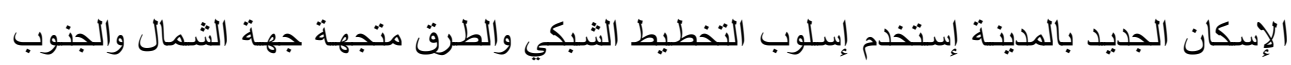
والثرق والغرب بمعنى أنها تحيط بالمباني وتساعدها على التظليل الجيد والتهوية الجيدة صيفاً وذلك بمحيطها الخارجي الزراعي. 


\section{3-4 المنطقة القديمة بمدينة القطن:}

من الخريطة الإقليمية لوادي حضرموت يلاحظ مرور الطريق الرئيسي الذي يربط بين مدنه الأربعة ماراً بمدينة القطن مخترقاً المنطقة القديمة والتاريخية والتي تقع ملاصقة للهضبة الجنية الجنوبية للوادي.

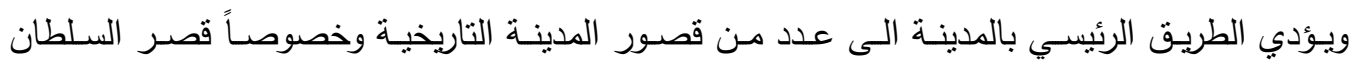

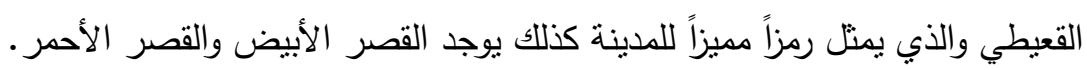
ويعتبر الطريق الرئيسي الذي يمر بالمنطقة التاريخية ويتجه من الغرب الى الثرق قادما من مدينة المكلا

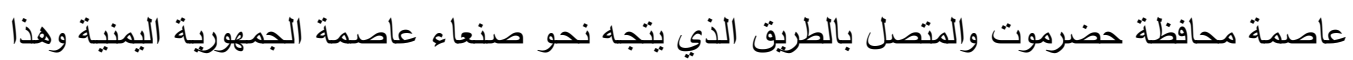
الإتجاه بشكل وجود المباني السكنية والخدمات حيث بطل عليه وتقع عليه طرق فرعية جهة الثمال

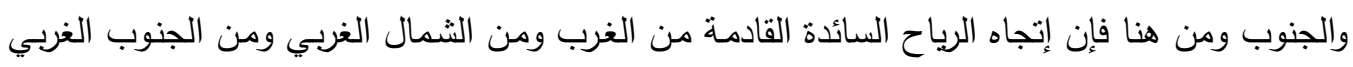

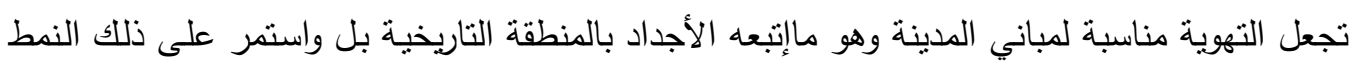

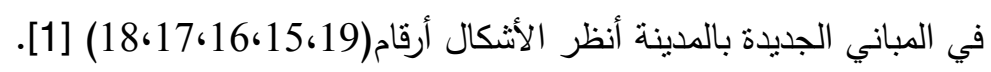
4 : طرق تطوير ومعالجات المناطق التراثية في مدن وادي حضرموت: 1-4 : مدينة شبام (منطقة شبام القديمة):

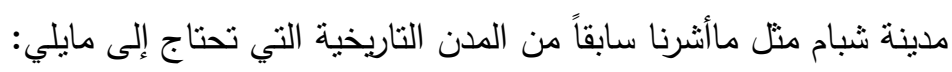

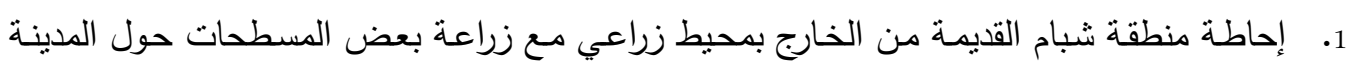
التاريخية. 2. تحتاج الى العلاج المروري والبيئي حيث حركة المرور وتأثيرها السلبي على المباني، وذلك بإبعاد طرق المرور الإقليمي. 3. يفضل عمل سور حجري سميك وقوي حولها للحماية من المؤثرات البيئية مثل السيول التي أثرت وتؤثر على الحوائط الساندة للسور الخارجي.



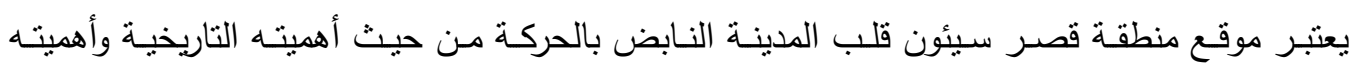

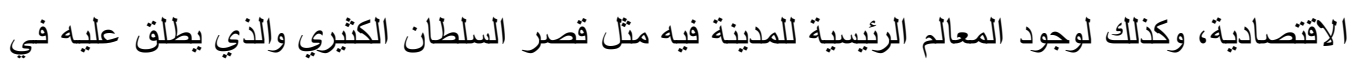

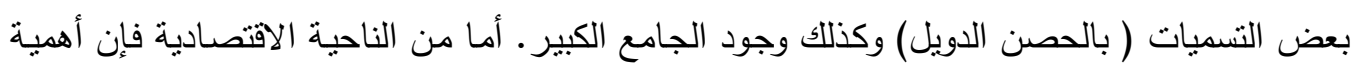

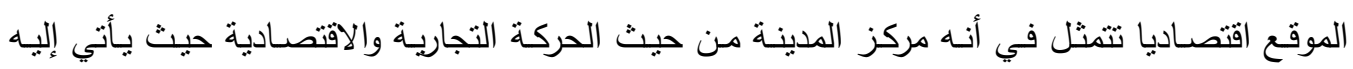

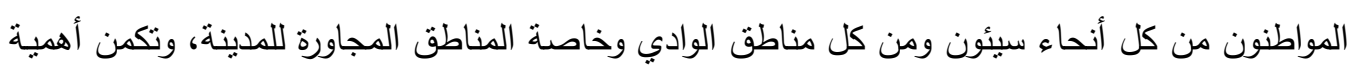

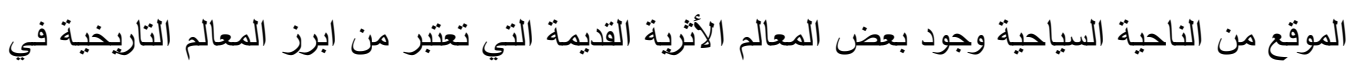
اليمن وهو قصر السلطان الكثيري ( الحصن الدويل) والجامع الكبير وغيرها من المعالم الأثرية.....الخ. 
مركز مدينة سيؤن مدينة قديمة ذات طراز معماري وتخطيطي قديم وكذللك النسيج العام اللمركز ينميز

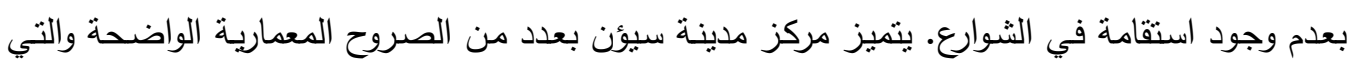
تأخذ أهميات متفاوتة والتي تعد من أهم المعالم البارزة في المدينة وهي:

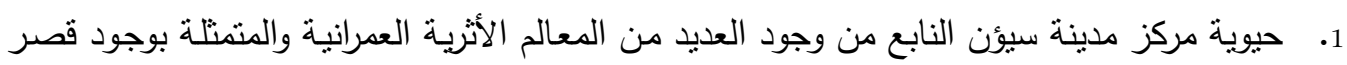

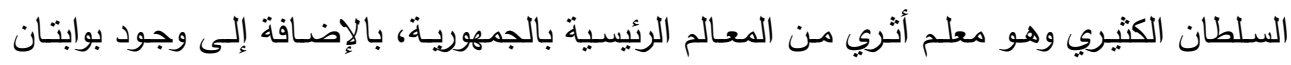

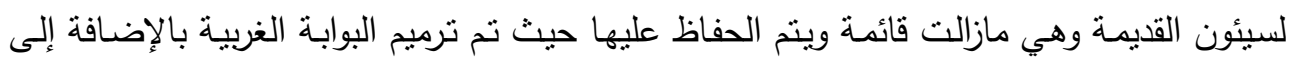
العديد من العالم الأثرية الأخرى. 2. وجود مجمع قضائي حديث يضم ثلاثة مباني.

3. وجود مبنى الإداره المحلية بالمديرية ضمن المركز والذي يوجد في مبنى قديم نم ترميمه حديثا.

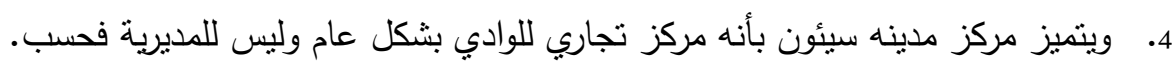

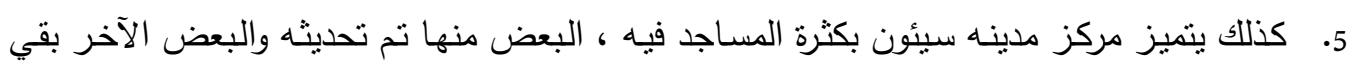
على ما هو عليه. 6. كما يوجد بمركز المدينة حديقة عامه بجوارها جزء به زراعة ونخيل كما توجد خدمات بوفيه وتوجد دراسة الآن لتطوير الحديقة مستقبلا. 7. كما يوجد في الجهة الثمالية من مركز الددينة مطار سيؤن والذي سيكون في المستقبل مطاراً دولياً.

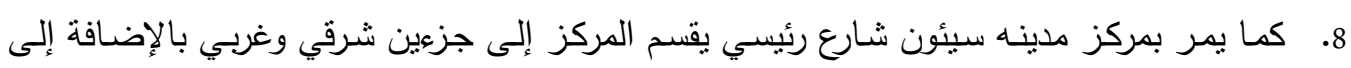

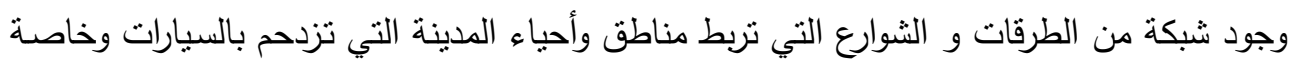
في وقت الظهيرة وذلك لوجود العديد من الدوائر الحكومية والمؤسسات الني تقدم الخدمة لمديريات

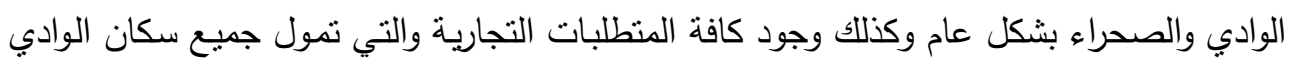

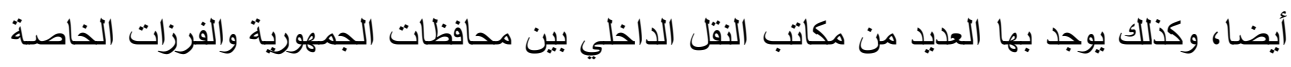

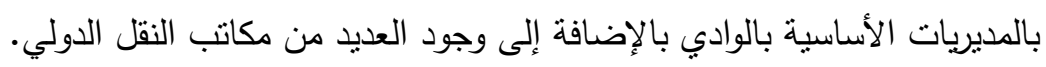

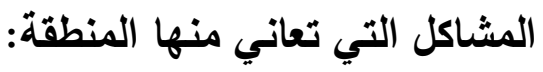

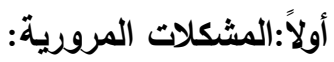
1. عدم توفر المواقف اللازمة للسيارات وخاصة بالقرب من منطقة القصر .

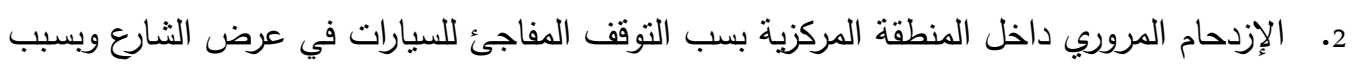
مرور الطريق العام داخل مركز المدينة. 3. وجود محطات النقل الدولي البري داخل المنطقة والني تحتاج إلى ساحات واسعة لوقوف الحافلات التابعة لها فقد وزعت هذه المحطات بطريقة عشوائية غير مدروسة. 
4. زحف البيع العشوائي على حافات الثوارع والأرصفة مما أدى إلى ضيق الشوارع وتداخل حركة

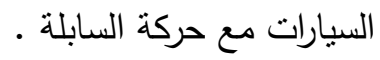
5. وإحدى أهم المشكلات التي نعاني منها المنطقة هي العقد المرورية ( الجولات وتقاطعات الثوارع) التي كثيرا ما تسبب إرباكا للحركة المرورية واختتاقات مرورية بسبب سوء التهبية التخطيط وافتقاد المنطقة

$$
\text { للإثشارات المرورية الضوئية. }
$$

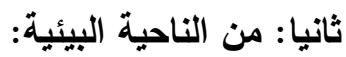

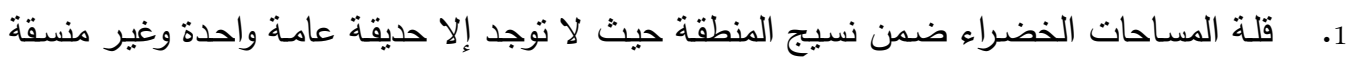

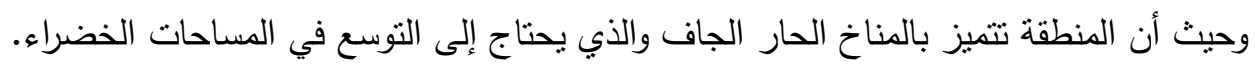

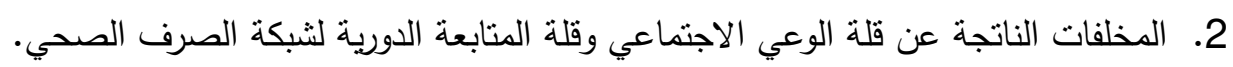
ثالثاً: من الناحية الاجتماعية: المنات

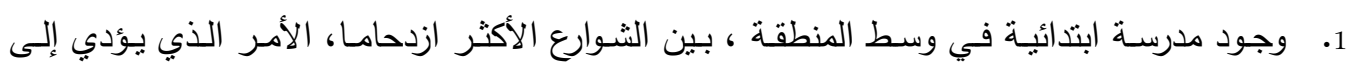

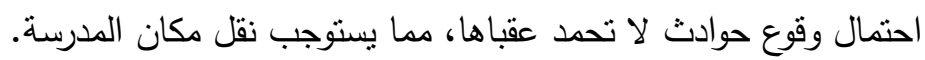
2. ت تداخل حركة المثاة مع حركة السيارات.

3. عدم وجود حدائق منسقة وأبنية لإقامة الاحتفالات والمناسبات والنزهة.

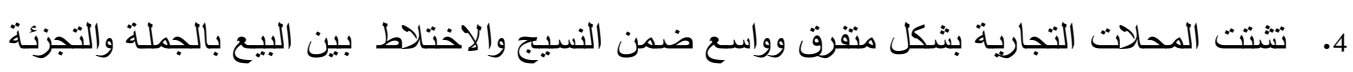
وهذا يشكل عبء كبيرا على المشتري.

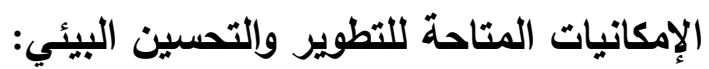

يمكن تقسيم الإمكانيات المتاحسة إلى قسمين هي: إمكانيات مستغلة، وإمكانيات غير مستغلة ويمكن توضيح ذللك كمايلي: الإمكانبات المستغلة: 1. وجود القصر واستغلاله في عملية الجذب السياحي. 2. استغلال القصر كعنصر بصري مهم في توجيـه محاور الحركـة الرئيسية والتأكيد على الهيمنـة البصرية له.

3. كون المنطقة في قلب المدينة واستغلالها كمركز تجاري.

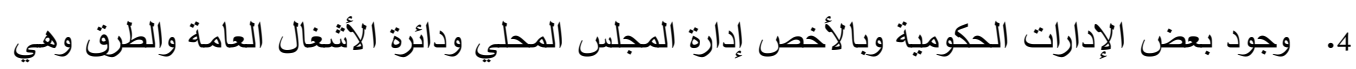
وظيفة تتاسب مركز المدينة .

الإمكانيات غير المستظلة: 1. نقل المحكمة إلى الموقع الجديد واستغلال الموقع لوظيفة جديدة. 
2. الاستفادة من موقع الحديقة بإعادة تتسيقها حتى تكون منطقة ترفيهية للسكان.

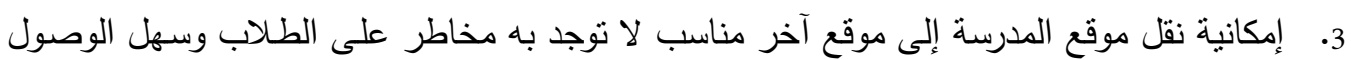
إليه. 4. إمكانية تتظيم سوق الخضار القديم. 5. إمكانية تنظيم العقد المرورية (الجولات) وإقامة بعض الفضم الرموز المعمارية بها. إستراتجيات الحلول:

1. تحويل الطريق الإقليمي المار بالمنطقة إلى شارع رئيسي وتحول الحركة الإقليمية إلى شارع المطار . 2. نقل المدرسة إلى موقع آخر مناسب واستغلال الموقع لوظيفة جديدة. 3. التوجيه باستخدام الطابع المحلي في إنهاء واجهات المباني وخاصة المحيطة منها بالقصر .

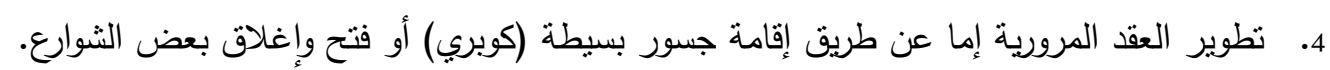
5. تنظيم البيع العشوائي وتخصيص مساحة خاصة لهم. 6. تحويل بعض المواقع إلى مواقف للسيارات. 7.

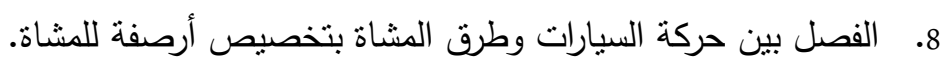
9. التسقيف لبعض الثوارع التجارية وتحويلها إلى مسارات للمشاة. 10. تحسين واجهات المحلات التجارية الموجودة على الثوارع الرئيسية للمنطقة وللساحات.

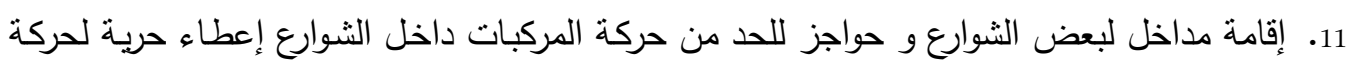

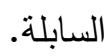

12. تتظيم السـاحة الخاصـة بوقوف حـافلات النقل السياحي بحيث تعكس الصـورة المطلوبـة للمدينـة للوافدين إليها ولا تؤثر في نفس الوقت على الحركة المروية في المنطقة الأشكال رقم (26،25،27).

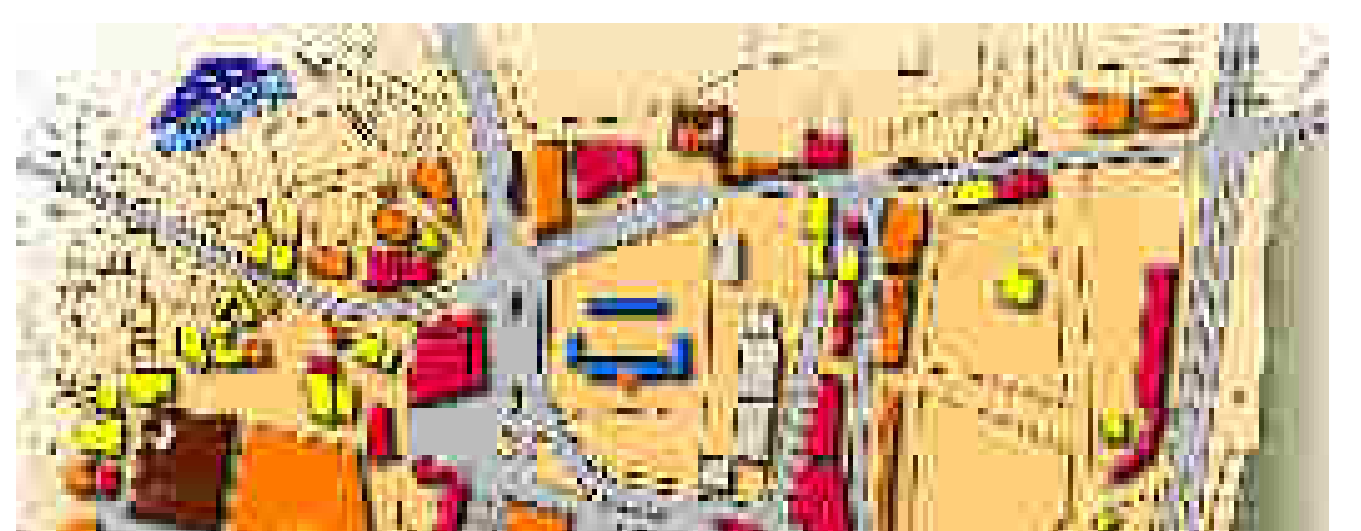


شكل رقم (25) يوضح منطقة قصر سيئون والمحيط العمراني المحيط به (الوضع الراهن)

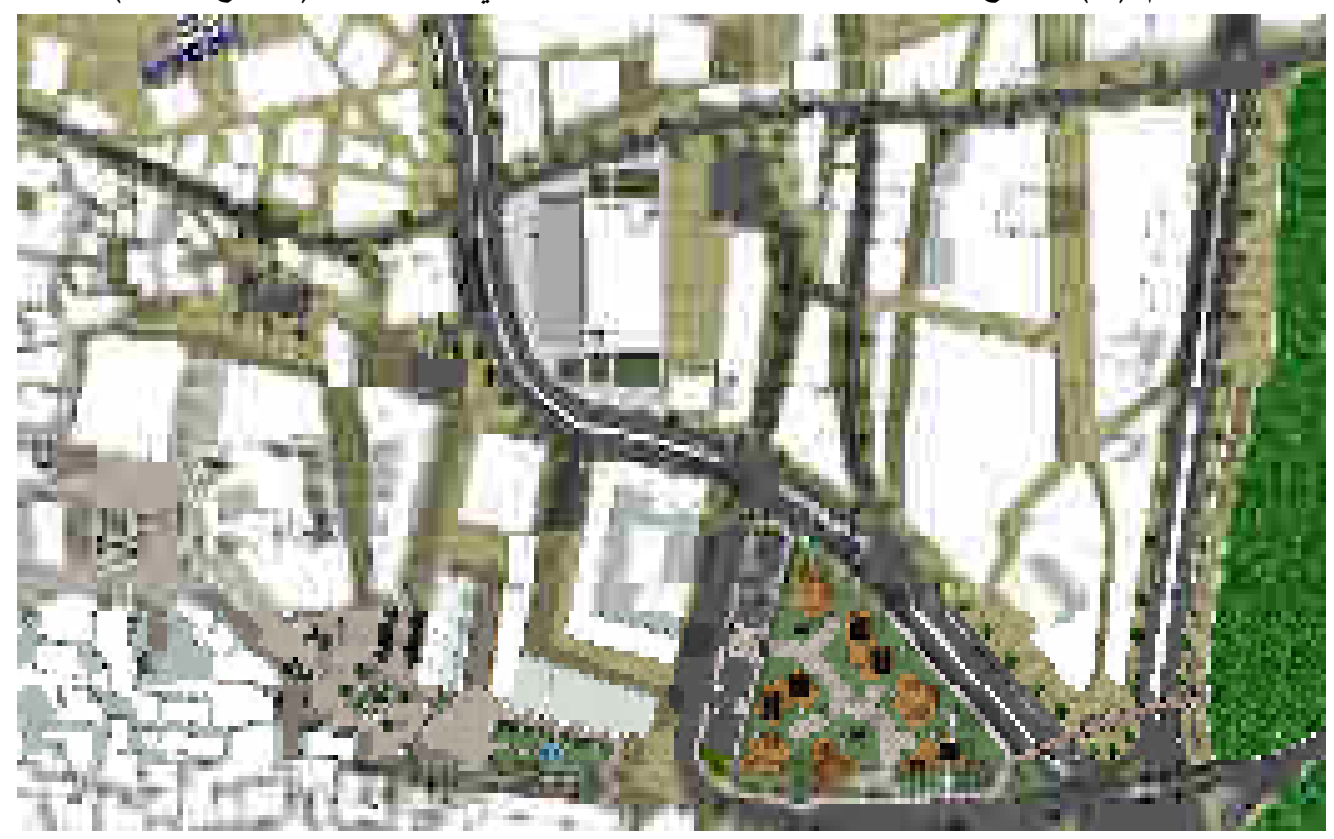

شكل رقم (26) يوضح محاولة تطوير المنطقة وإظهار موقع قصر سيئون وتحسين وتخطيط المنطقة
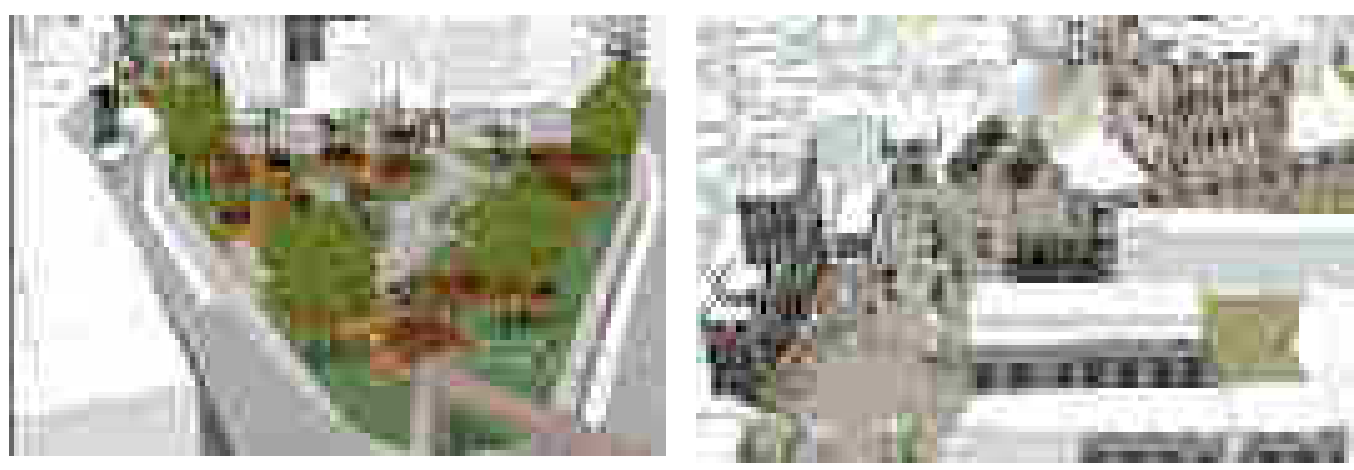

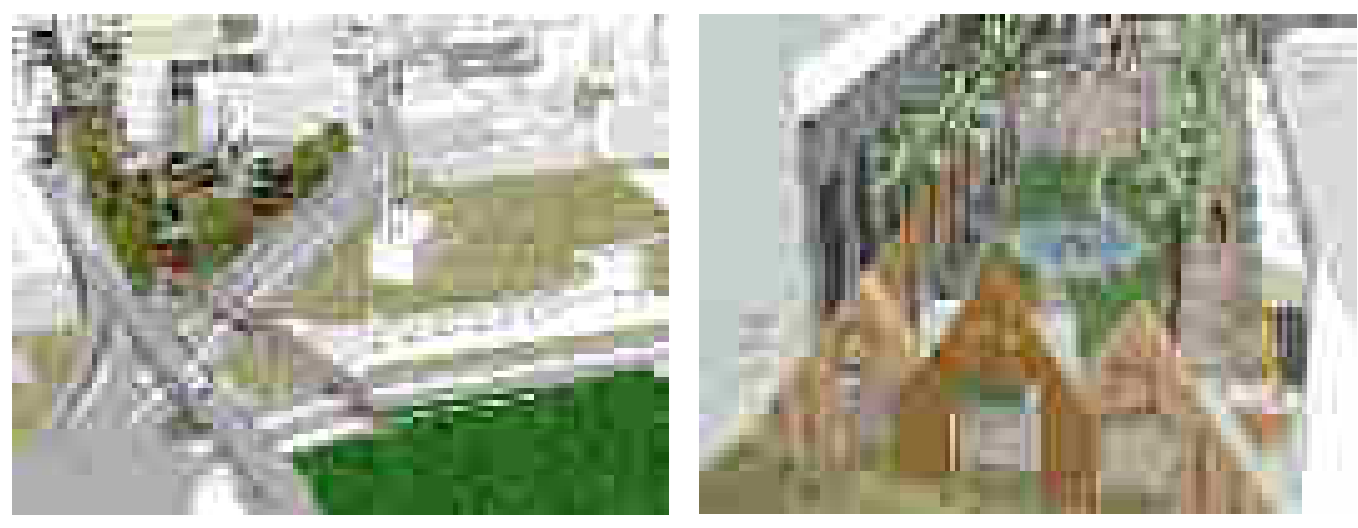

شكل رقم (27) يوضح صور من التجميل للموقع وتطويره وإظهار موقع قصر سيئون وتحسين وتخطيط المنطقة

4-3 : مدينة تريم (منطقة قصر الرناد):

تقع المنطقة ضمن الأحياء القديمة للمدينة حيث تحتل جزء كبير من مركز المدينة وتتحدد المنطقة من

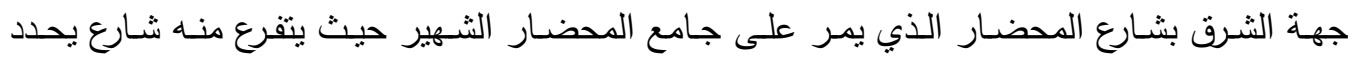

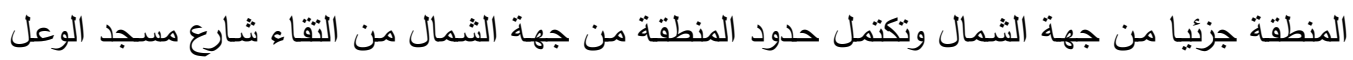

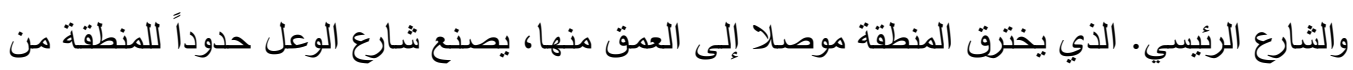

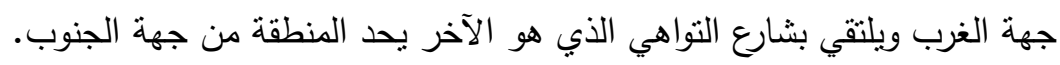

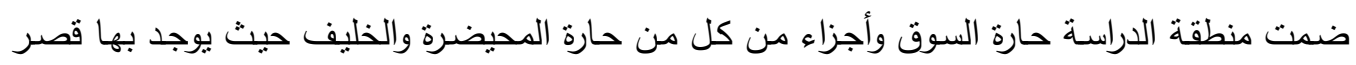

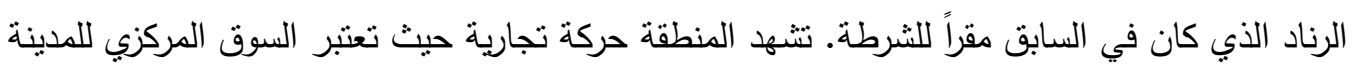

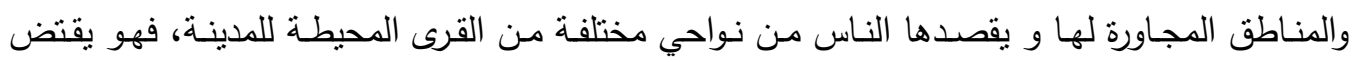
بالمنسوقين في فترتي الذروة، الفترة الصباحية من الساعة التاسعة صباحاً وحتى الساعة الثانيه ظهراً وبالليل من الخامسه عصراً وحتى بعد العشاء. فئرئ. تتكون أرضيات الفضاءات الحضرية من أرضيات نرابية وهناك أجزاء مرصوفة باء بالحجارة أمسا الثشارع

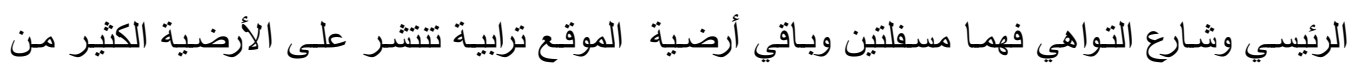

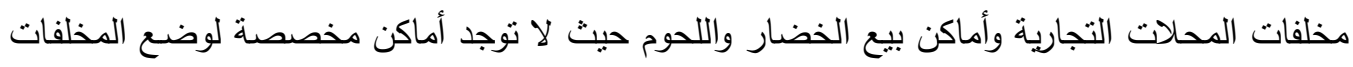

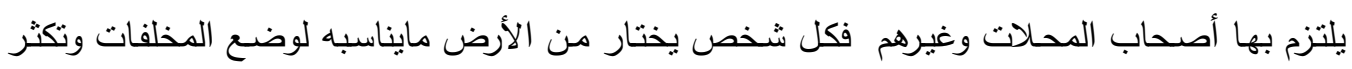
مثل هذه الفوضى في سوق الخضار واللحوم وتسبب إيذاء لزائر المنطقة وتنشوَه حضرياً. 
هناك بعض الفراغات الأخرى البسيطة والتي تستخل استغلالاً سيئًا مما يعكس صورة حضرية غير جيدة للموقـع، ويلاحظ نـدرة وجـود السـاحات والفراغـات الخارجيـة في الموقع، وتعتمـد المبـاني في إضـاءتها وتهويتها على الأزقة الضيقة وبعض الأفنية الداخلية، وتعتبر ساحة القصر الفراغ الوحيد الذي يظهر بوضوح في المنطقة. معظم واجهات المباني السكنية مـن الطين وهي واجهات صلدة في الغالب لا تحتوي على أي بروزات أو خسفات وهناك بعض الأبنية المليسـة بالنورة و تحتوي على نقوش وزخارف

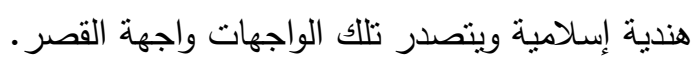

\section{المشكلات التي يعاني منها الموقع:}

1. ضيق المسار الرئيسي المودي إلى ساحة القصر في بعض الأماكن.

2. فقدان أرصفة المشاة، وإن وجدت فإنها تشتعمل لأغراض أخرى منل الباعة المتجولين و غيرهم. 3. اختلاط حركة المشاة بحركة السيارات في المسارات الرئيسية بشكل كبير مما يسبب ازدحام مروري

$$
\text { وخاصة في وقت الذروة. }
$$

4. الأكثاك التي توجد على حواف بعض الثوارع تؤدي إلى حدوث ازدحام بالإضـافة إلى إنها تقلل من العلاقة البصرية للشارع (منل الأكثاك حول القصر). 5. الحالة الردئية لبعض الواجهات والتي توثز على جمال المنطقة.

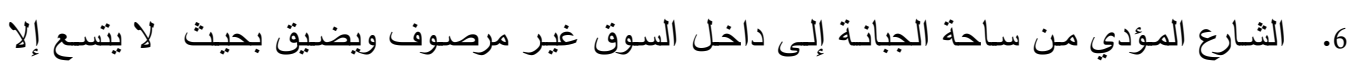
لمرور سيارة واحدة دخولا أو خروجا. 7. التداخل والفوضى فى معالجة حوائط وأرضيات وأسقف الفراغات. 8. ت تهور بعض الأبنية التراثية وعدم الاهتمام بها مما يهددها بالزوال. 9. ظهور عدد من ألأبنية الخرسانية التي تهدد الهوية المعمارية للمنطقة.

\section{الإمكانيات المتاحة للتطوير والتحسين البيئي:}

1. استغلال الساحة الموجودة شرق ساحة قصر الرناد بعمل موقف للسبارات كما يمكن إضـافة بعض

$$
\text { المباني الخدمية الضرورية. }
$$

2. توسيع الشارع المتفرع من شارع المحضار بحيث يتم تأهيله وإزالة بعض الأبنية المهدمة . 3. تحويـل القصـر إلـى مبنى سياحي بمـا يسـاهم بـالنهوض بالمنطقـة واسـتغلال السـاحة التي أمامـهـ كساحة مركزية خالية من كل التجاوزات الموجودة حاليا وإعادة رصفها وتتظيمها. 
4. إقامة سوق مركزي للخضار والفواكه على أنقاض السوق الحالي يلبي رغبة الباعة والمشترين ويحل

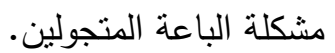

5. تأهيل الفندق المطل على ساحة القصر وجعله بدرجة سياحية مناسبة لخدمة السياحة الأجنبية.

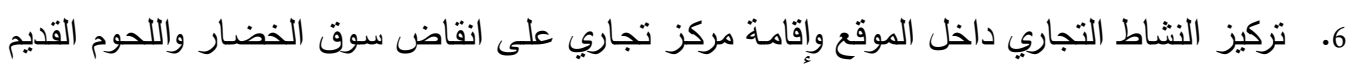

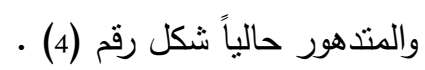

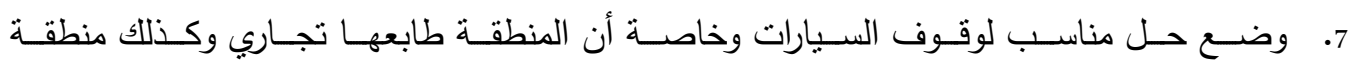
المسجد(الجامع) الذي يحتاج إلى مواقف وساحات.

\section{إستراتجيات الحلول:}

1. - حماية المنطقة من الطرز ومواد البناء الدخيلة.

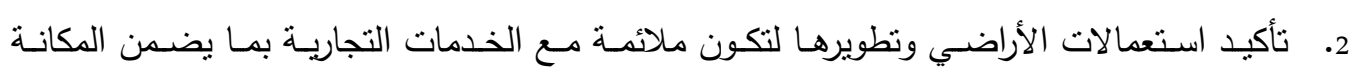
التاريخية للمنطقة .

3. اقتراح أبنية تنساعد في نهضة المنطقة وتأهيل الأبنية التراثية الموجودة فيها. 4. دراسة محاور الحركة وتسهيل عملية الدخول والخروج من الموقع والفصل بين التداخلات المرورية.

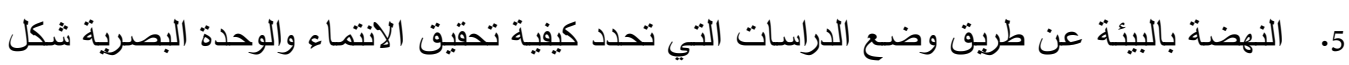

$$
\text { رقم (30،29،28). }
$$

\section{4-4 مدينة القطن (منطقة وسط المدينة والقصر):}

تعرف منطقة وسط المدينة والقصر بالمنطقة المركزية التجارية لمدينة القطن وهي السوق القديمة للمدينة القديمة ذات التخطيط المتضام وكذللك كانت المركز الإداري الحكومي للسلطنة القعيطية، وتتركز في هذه ولهن

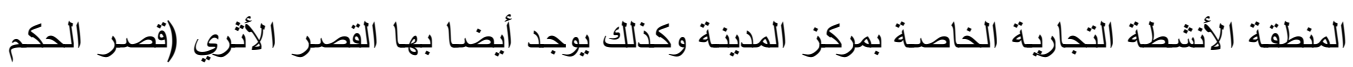
اللسلطان القعيطي) بالقرب من المسجد الجامع للمدينة القديمة.

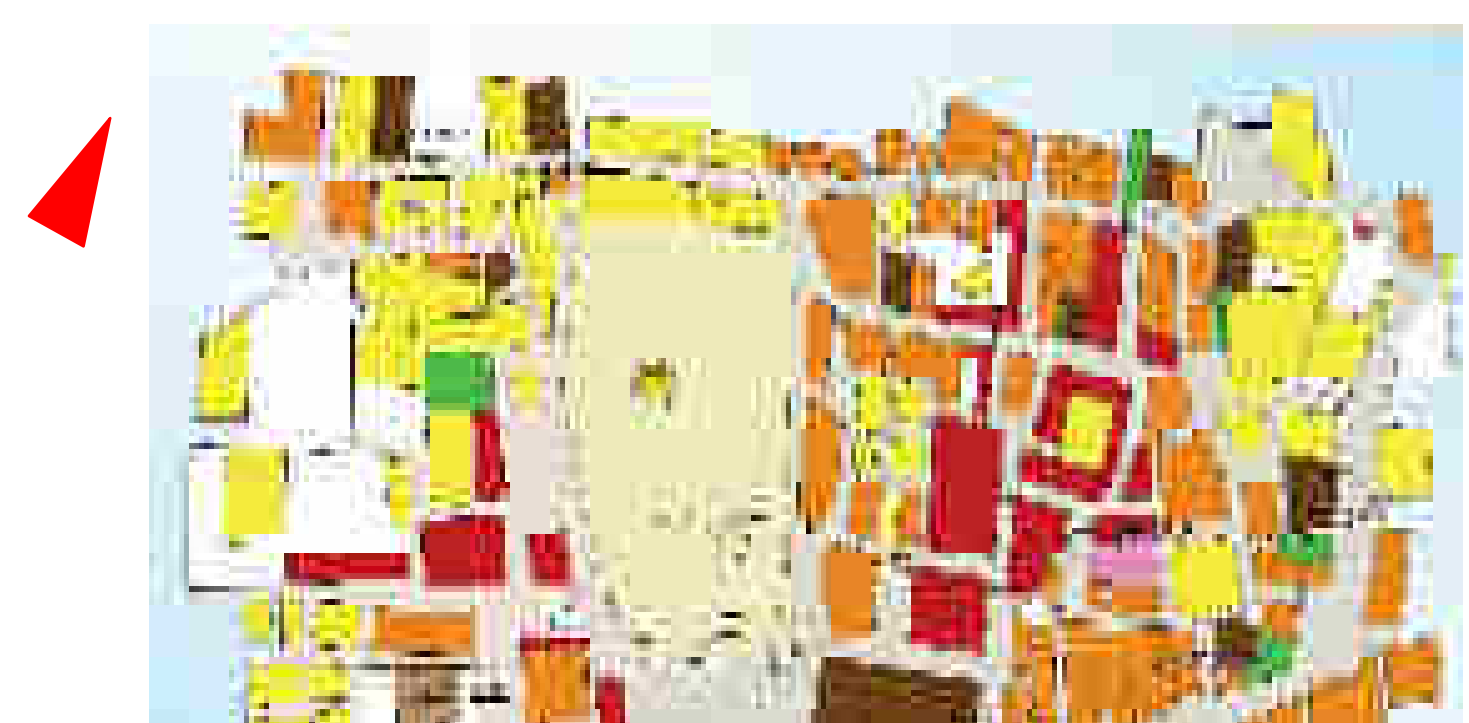


شكل رقم (28) يوضح منطقة قصر الرناد ومنطقة وسط مدينة تريم (الوضع الراهن)

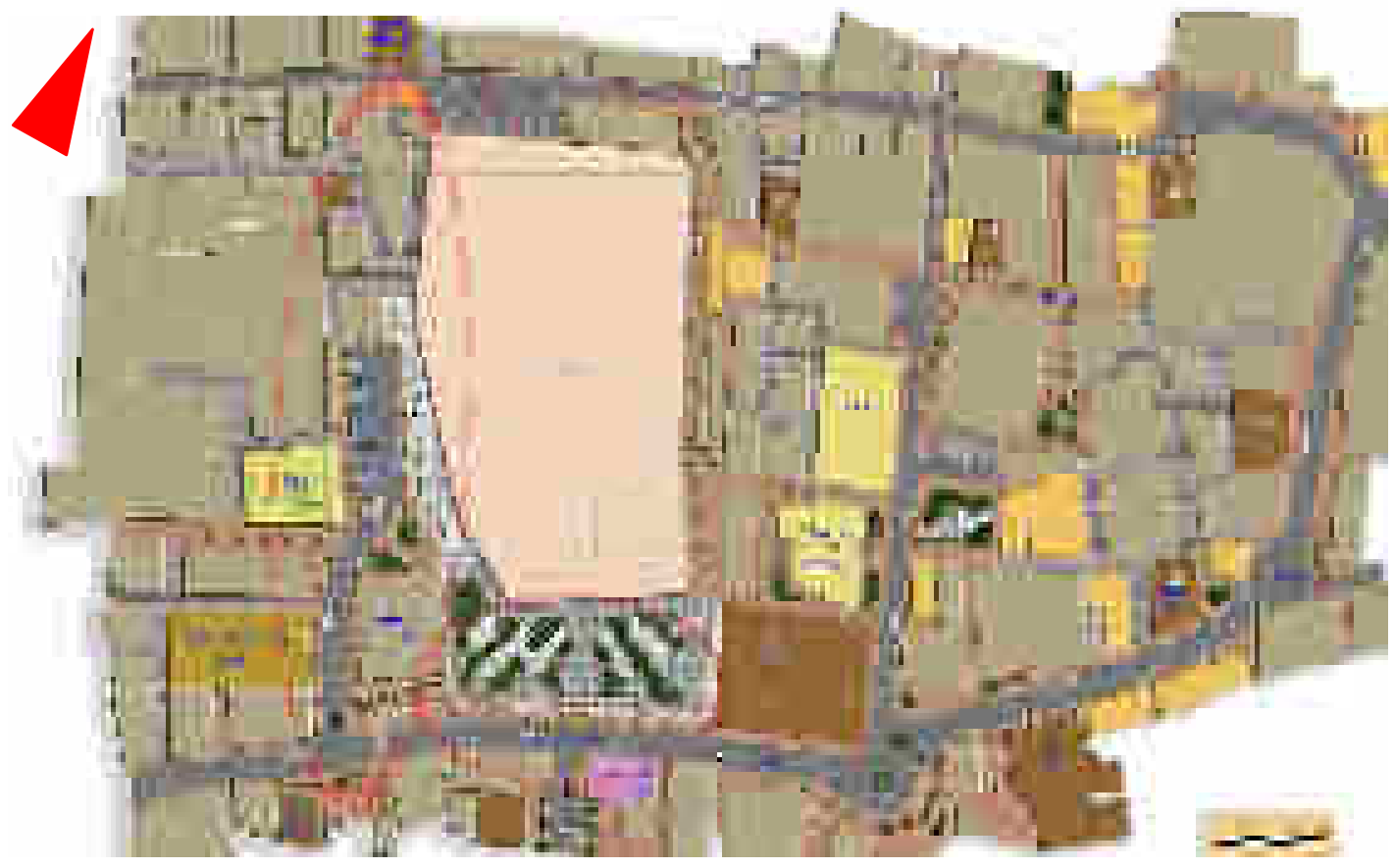

شكل رقم (29) يوضح محاولة تطوير منطقة قصر الرناد بمدينة تريم
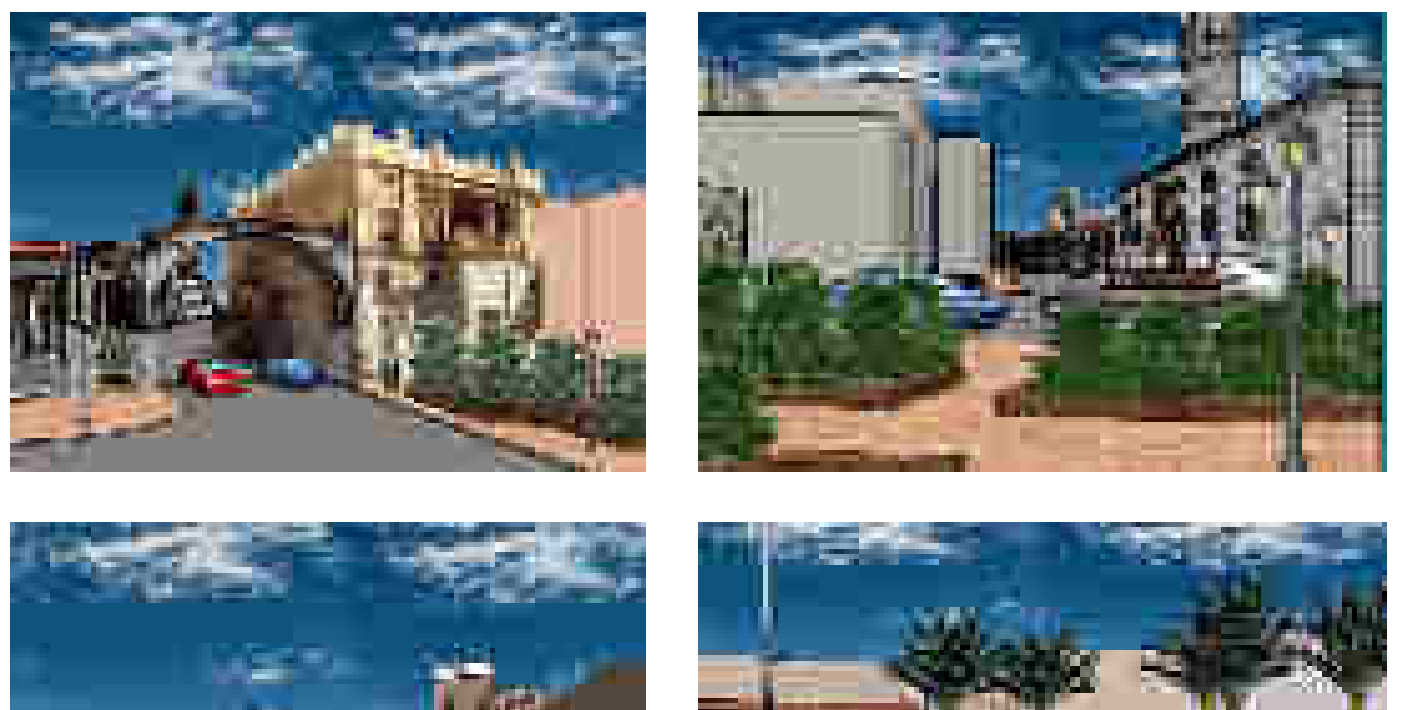
شكل رقم (30) يوضح صور من التجميل للموقع وتطويره وإظهار موقع مسجد الجامع وتحسين

\section{وتخطيط المنطقة}

وهذه المنطقة تضم عدداً متتوعا من الإستعمالات ويمتد الإستعمال التجاري في المنطقة على شكل

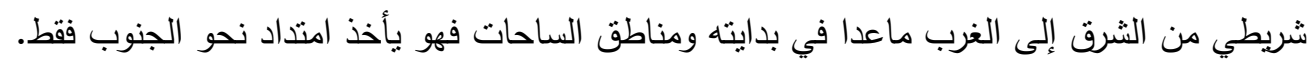

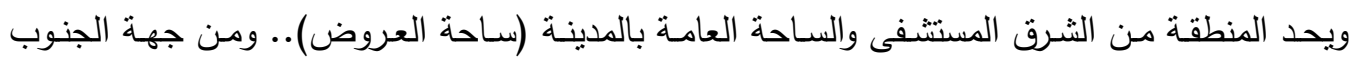

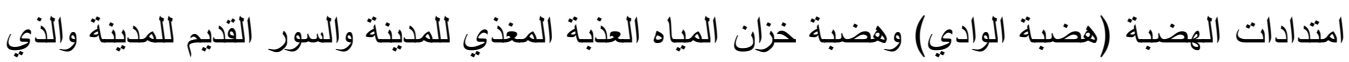

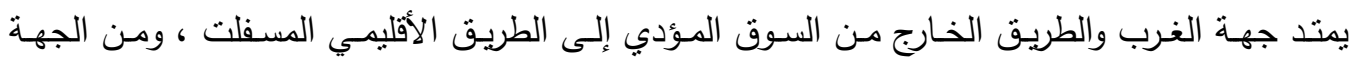
الثمالية مجموعة الأبنية السكنية. وتتمتع المنطقة بثلاثة مقومات ومزايا هي: 1. الطابع التجاري المركزي على مستوى المدينة.

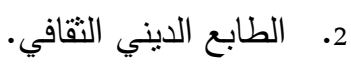
3. الطابع السياحي( إذا استغل بشكل جيد). المشكلات التي يعاني منها الموقع: 1. وجود الطريق الإقليمي الذي يخترق المنطقة. 2. فقدان أرصفة المشاة، وإن وجدت فإنها تستعمل لأغراض أخرى كالباعة المتجولين.

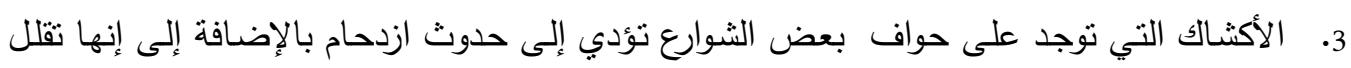
من العلاقة البصرية للثارع.

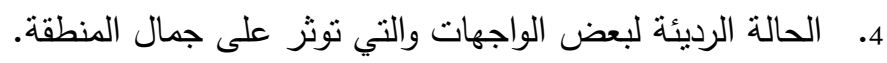
5. التداخل والفوضى فى معالجة حوائط وأرضيات وأسقف الفراغات.

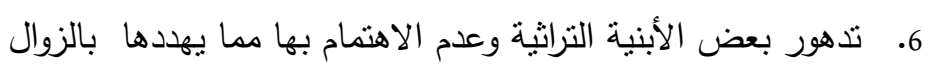
7. ظهور عدد من ألابنية الخرسانية التي تهدد الهوية المعمارية للمنطقة. 
8. عدم الفصل في الحركة ( ذهاباً إيابا ). 9. عدم إنجاز عمليات توسعة في مناطق وإختناقات المرور .

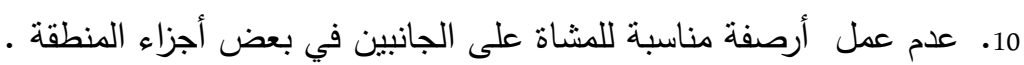
11. عدم وضع حل مناسب لوقوف السيارات على الثوارع.

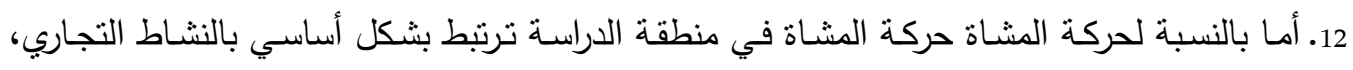
ويلاحظ اختلاط حركة المشاة بحركة السيارات في المسارات الرئيسية بشكل كبير مما يسبب التبط ازدحام

$$
\text { مروري وخاصة في أوقات الذروة. }
$$

13. سوء حالة معظم المباني الملاصقة للقصر من جهة الثمال وهي عبارة عن ركام من الطين وفي أحسن الأحوال جدران قائمة فقط.

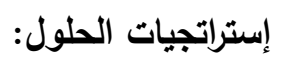

1. منطقة وسط الددينة والقصر التي تعد من المناطق الهامة وجعلها مناطق لحركة المشاه. 2. تحسين البيئة بالزراعة والأثجار والممرات وأعمدة الإنارة. 3. خلق مناخ بيئي للزيارات والإستخدام المميز لهذه المباني الهامة سياحياً.

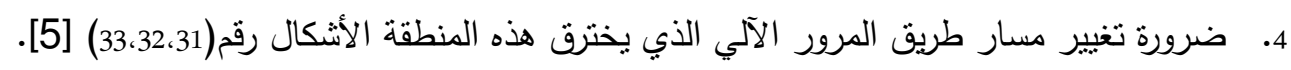


$\triangle$

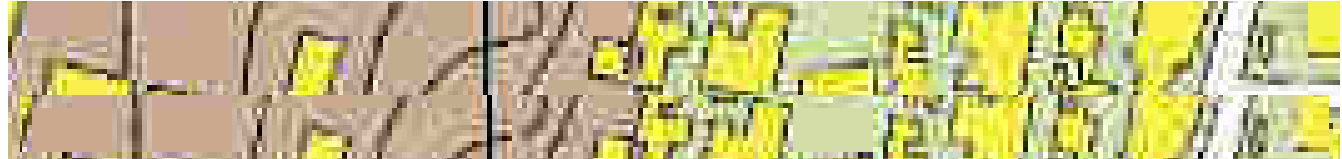

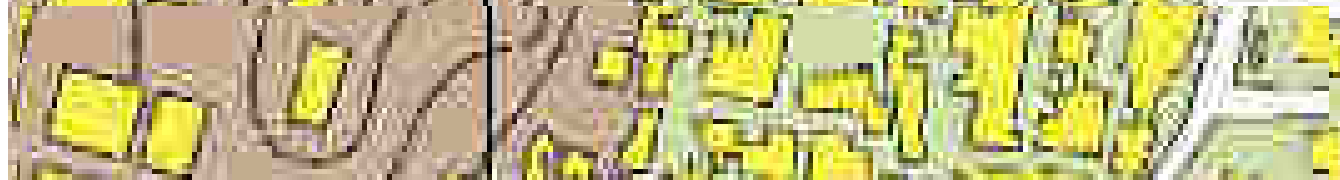

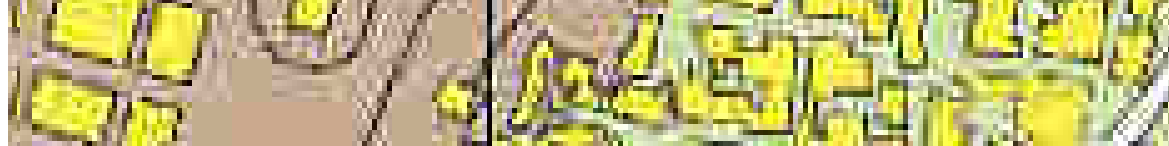

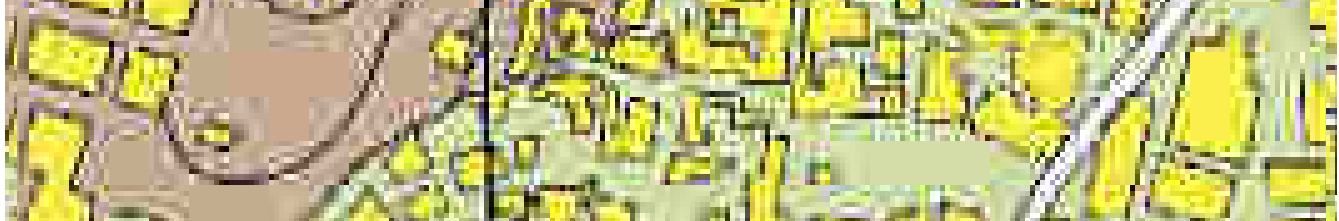

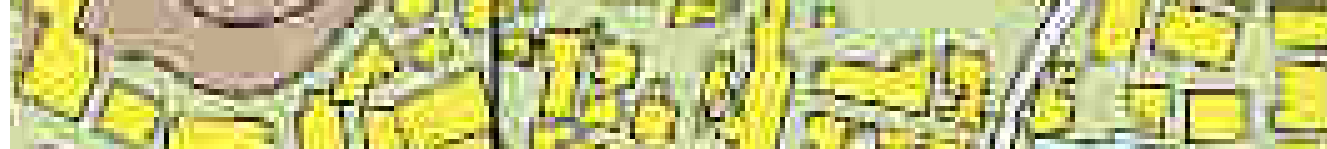

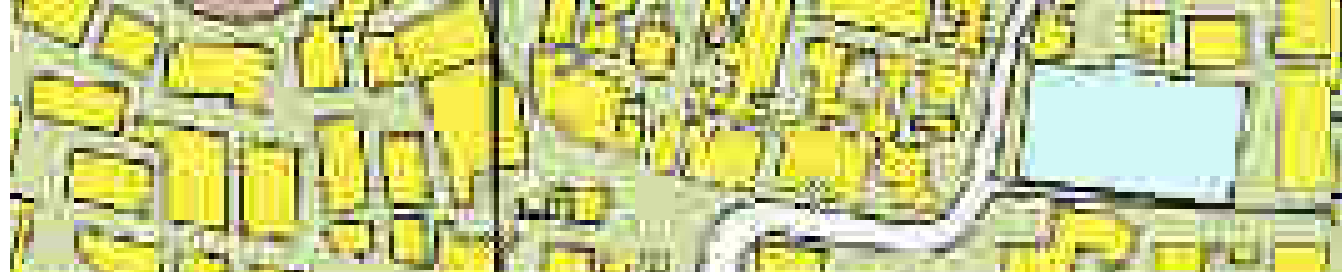

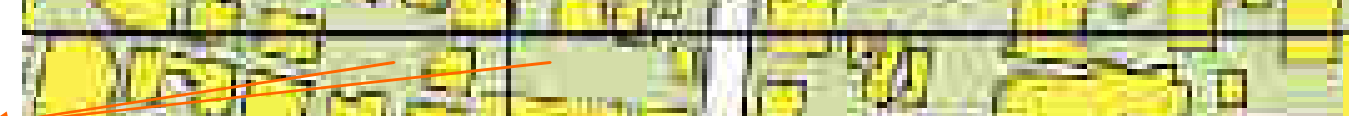

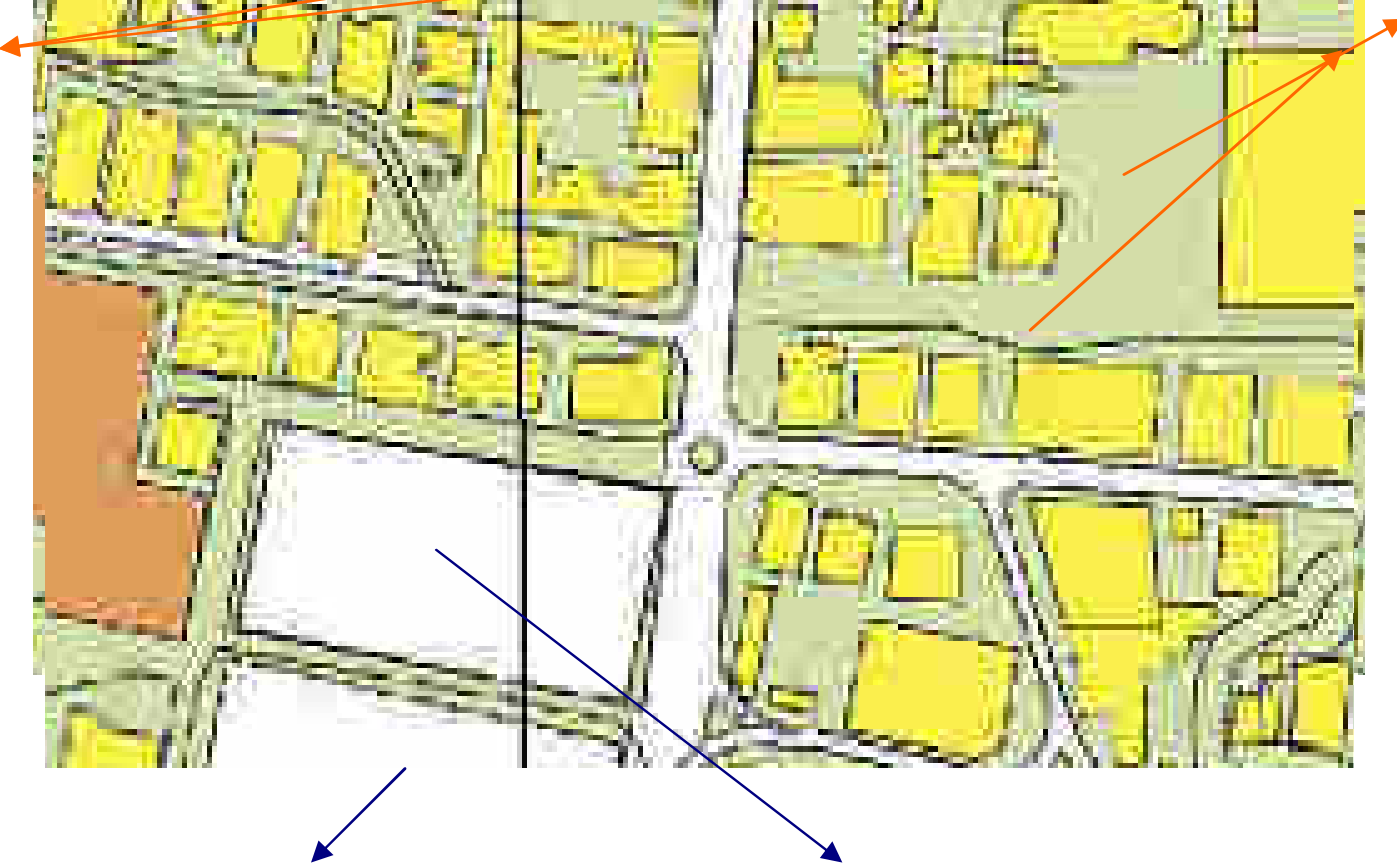

شكل رقم (31) يوضح منطقة وسط مدينة القطن والقصر والمنطقة المحيطة (الوضع الراهن) 


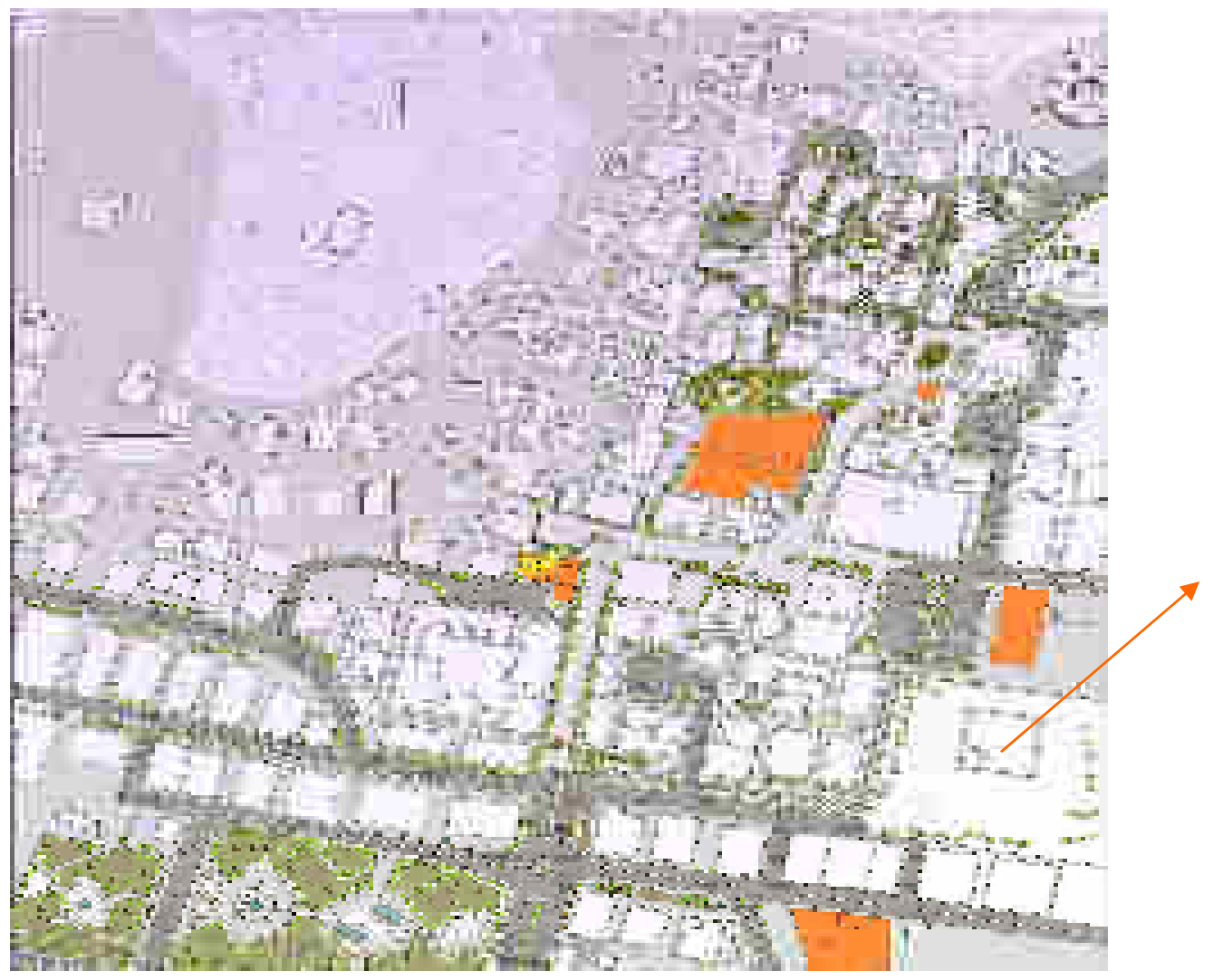

شكل رقم(32) مشروع تطوير المنطقة محاولة ومقترح للتطوير والتحسين العمراني والبيئي
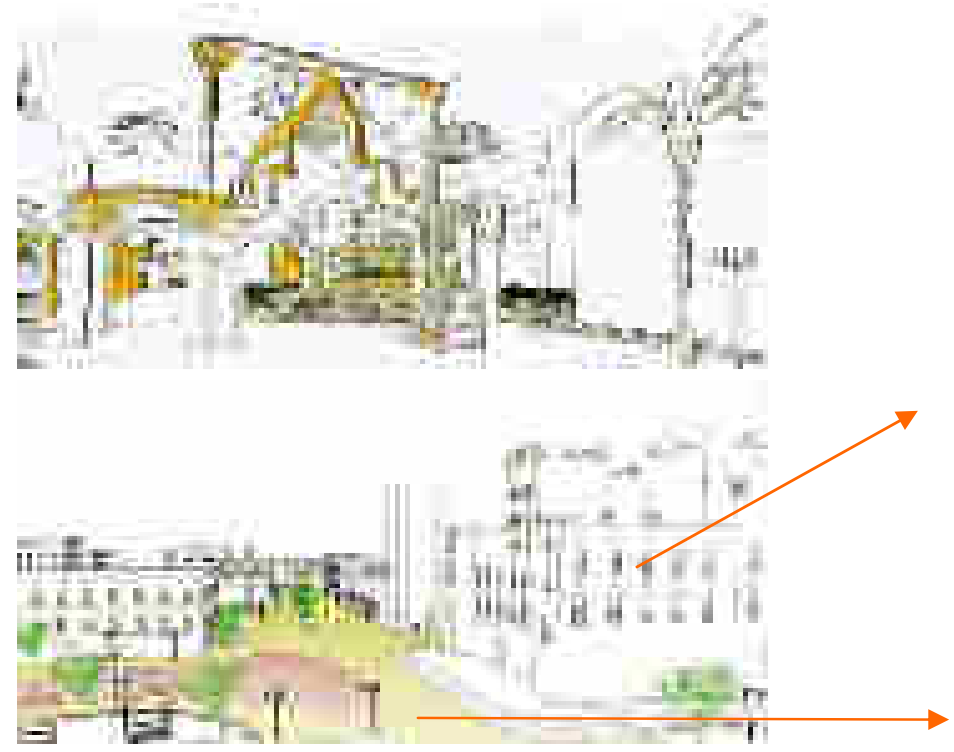


\section{شكل رقم (33) يوضح صور لمقترحات التطوير لمنطقة القصر والبوابة}

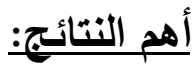

نستخلص من البحث أهم النتائج التي لها أثر فعال في تحقيق الهدف من البحث وهي كلآتي:

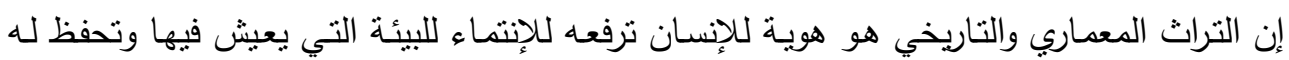

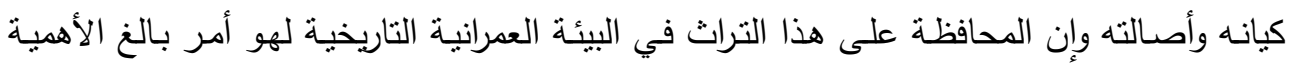
للإنسان والمجتمع. إن المنـاطق التاريخيـة لهـا طبيعـة خاصــة وطـابع مميز ينبغـي المحافظـة عليـهـ وتتميتهـه وتطويره للأفضل في عصر التتمية الذي يعيشه سواء للإنسان أو المجتمع أوالبيئة.

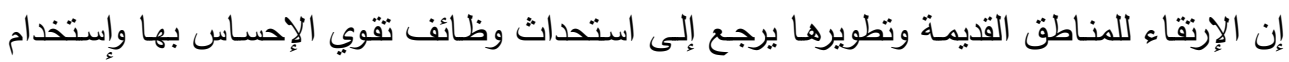
المباني المميزه فيها في أنشطة عصرية لهو المدخل الحقيقي للتطوير والإرتقاء. إن تهيئة البيئة المحيطة بالعنصر المعماري التاريخي المميز للقصور التاريخية للسلاطين وملوك لهئه الدولة وتزيين مداخلها وساحاتها بالنباتات والزهور الطرقات المجهزه المزينة بالبوابات أحواض الزهية الزهور هو أمر يحقق البيئة الجيدة والمريحة في تلكك المناطق الحارة.

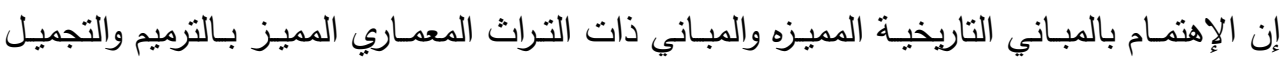
يعطي صفة الإنتماء لهذه المدن وتصبح مصدر فخر لأهلها فضلاً عن الإستفادة باستخدامها.

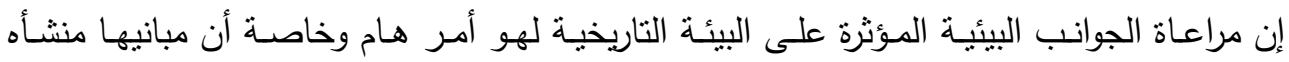

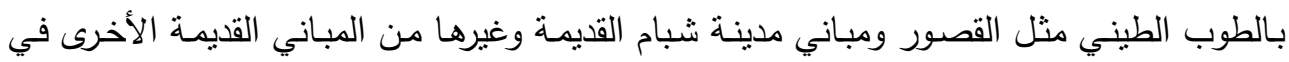

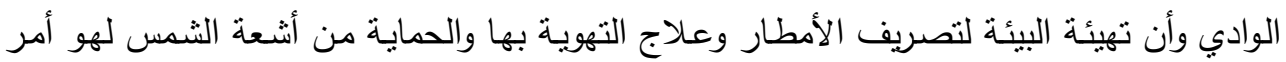
بساعد على حسن إستخدامها وخلق مناخ جيد لأهلها وللزوار من السياحة الداخلية والخارجية. أهم التوصبيات:

أن يتحقق الإهنمام بتلك المناطق والمباني ذات الصفة التراثيـة والتاريخية بمدن وادي حضرموت بتفعيل العمل البيئي بها وحمايتها والإرتقاء بها.

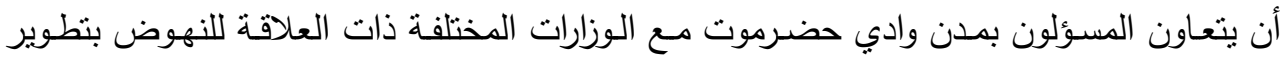
وتتمية نلك المناطق التاريخية الهامة ذات التراث العئ العريق. أن يراعى تطوير البيئة وتتزينها بالعناصر الجمالية والزهور والأشجار المناسبة وكذلك طرق المشاه وبالثكل المعماري المناسب لها. أن يتم وضع هذه المباني والمناطق الثراثية على خريطة اليمن السياحية وإعثبارها مزارات سياحية

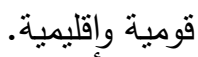


أن يتحقق الإستثمار الحقيقي لتلك المناطق بتفعيل إستخدام القصور والمناطق في إحياء التراث وجعلها متاحف أوتنتخدم إستخدامات قوميـة لنشر الثقافة والمعرفة للزائرين من السباحة الداخلية ولفية والخارجية.

إن الإهتمـام بالقصـور والمنـاطق التاريخيـة يستوجب أن ترصد لها ميزانيات خاصـة وإدارات بهذه المناطق أن تنن التتريعات المنظمة للأعمال التي تتم بها لحمايتها وصيانتها وإستخدامها. أن يتت نشر الوعي البيئي والنقافي لدى السكان بتلك المدن للإهتمام بتراثهم العريق ونشر أهمية المساهمة فيه والإرتقاء به والتعلم منه في فن العمارة والبناء والحضارة.

\section{قائمة المراجع العلمية:}

1. التخطيط الإقليمي لوادي حضرموت- جامعة حضرموت للعلوم والتكنولوجيا( فريق من الأساتذه

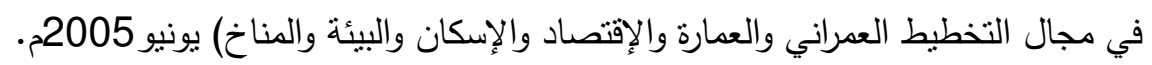

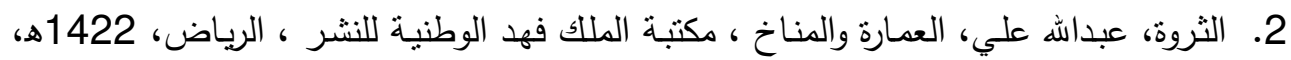

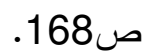

3. الخولي، محمد بدر الدين، المؤثرات المناخية والعمارة العربية، بيروت، 1983م، ص114.

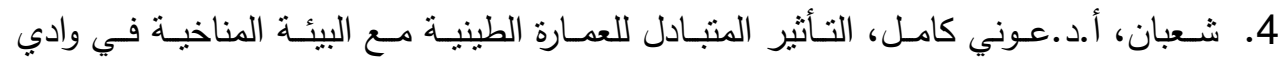

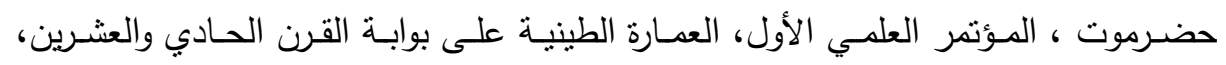

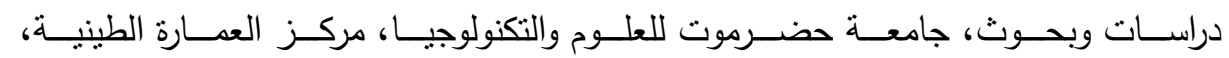

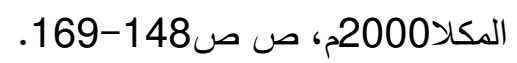

5. طلاب المستوى الخامس، مشاريع وأبحاث التخرج، تحت إثراف أساتذة قسم الهندسة المعمارية،

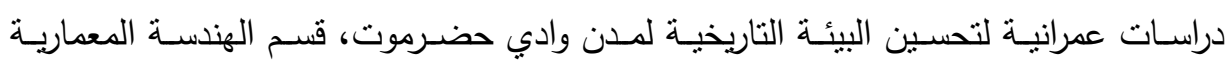

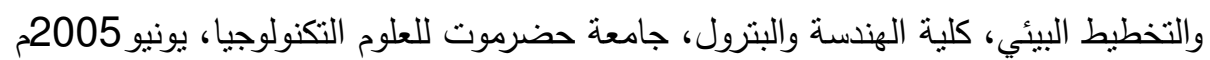

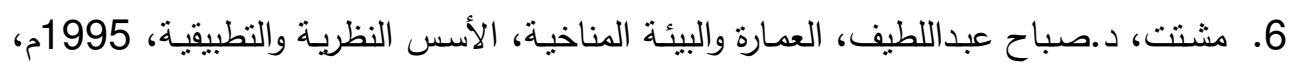

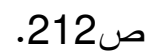
7. مشـروع الأعمـال الإستشــارية لتطـوير وادي حضـرموت، تقريـر المرحلـة الأولـى، جامعـة حضرموت للعلوم والتكنولوجيا، إبريل 2004م.

8. Dorothy Mackezie:"Green Design - Design for Environment " second edition , Laurence King, London ,England ,1997.

9. John G . Rau \& David C .Wooten : "Environmental Impact Analysis handbook ", M cGraw - Hill Book Company , New York,USA,1980. .

10. Ken Yeang : " Designing with Nature, The Ecological Basis for Architectural Design ", McGraw- Hill Book Company, New York ,USA1995. 
